\title{
Invasion history and demographic processes associated with rapid morphological changes in the Red-whiskered bulbul established on tropical islands
}

\author{
Ariane Le Gros ${ }^{1,2,3^{*}}$, Philippe Clergeau ${ }^{2}$, Dario Zuccon ${ }^{3}$, Raphaël Cornette ${ }^{3}$, Blake Mathys ${ }^{4}$,
} and Sarah Samadi ${ }^{3}$

Molecular Ecology - ISSN: 1365-294X - John Wiley \& Sons Ltd

doi: $10.1111 / \mathrm{mec} .13853$

The final publication is available at http://onlinelibrary.wiley.com/doi/10.1111/mec.13853/full

${ }^{1}$ Université Paris Diderot, Sorbonne Paris Cité, 5 Rue Thomas Mann, 75013 Paris, France

${ }^{2}$ Centre d'Ecologie et des Sciences de la Conservation (CESCO UMR7204), Sorbonne Universités, MNHN, CNRS, UPMC, CP51, 55 rue Buffon, 75005, Paris, France

${ }^{3}$ Institut de Systématique, Evolution, Biodiversité (ISYEB UMR 7205), Sorbonne Universités, MNHN, CNRS, UPMC, CP26, 57 rue Cuvier, 75005 Paris, France

${ }^{4}$ Ohio Dominican University, Division of Mathematics, Computer and Natural Sciences, Columbus, OH 43219, United States

*Corresponding author: Ariane Le Gros; ariane.le.gros@gmail.com

\begin{abstract}
The Red-whiskered bulbul is a very successful invasive bird species. Morphological differences have been reported among individuals inhabiting the humid and dry coasts of Reunion Island, in a 30-year-old population. This suggests a capacity for rapid local adaptation which could explain the general invasive success of this species. However, the origin and invasion history of this population is unknown. It is therefore not possible to establish with certainty the cause of these morphological differences. Here, we investigated the invasion history of populations of Red-whiskered bulbul established on Reunion Island, Mauritius and Oahu (three geographically similar tropical islands) to assess the link between invasion history and morphological changes in these populations. We first assessed the source(s) of the invasive populations. We then compared the morphology of the individuals between the invasive and native populations, and between the dry and humid coasts of invaded islands. Finally, we inferred the invasion history of the invasive populations to investigate the role of neutral processes (e.g. founder effect and drift) on morphology. We found that the invasive populations have a similar origin and that the morphology of the individuals in these populations has diverged in a similar way from the native range, suggesting a convergent adaptation to tropical islands. Like on Reunion, we found differences in morphology between the dry and humid coasts on Mauritius. These morphological differences can be explained by invasion history on Reunion but not on Mauritius. Both neutral evolution and adaptation thus shape the morphology of invasive Red-whiskered bulbuls.
\end{abstract}

Keywords: contemporary evolution, invasive species, neutral evolution, phylogeography, population genetics, Pycnonotus jocosus 


\section{Introduction}

The invasion history of a species established outside of its native range and the demographic processes following introduction events can impact the genetic diversity and thus the evolutionary trajectory of the newly established populations. For example, propagule pressure (i.e. the number of individuals introduced in a location) is classically positively correlated with genetic diversity in invasive populations (Lockwood et al. 2005; Blackburn et al. 2015). Multiple introductions can also increase genetic diversity, and admixture between individuals from different source populations can generate new genotypes (Dlugosch \& Parker 2008; Kolbe et al. 2008; Roy et al. 2015). Conversely, sequential introductions in new locations associated with bottlenecks and rapid range expansion can increase the impact of drift and decrease genetic diversity (Clegg et al. 2002; Dlugosch \& Parker 2008; Peischl \& Excoffier 2015). Changes in genetic diversity will in turn affect the evolutionary potential of an invasive population and thus its ability to spread where it has been introduced (Lee 2002; Bacigalupe 2008). Knowing the invasion history of populations introduced in new locations (i.e. date of introduction(s), number of introductions, propagule pressure, source population(s), demographic history, admixture) is thus an important element in designing control and prevention strategies against the spread of these populations (Estoup \& Guillemaud 2010; Jacquet et al. 2015; Rijal et al. 2015).

Recently, it has been suggested that rapid local adaptation is a factor enhancing the invasive success of introduced populations (Lee 2002; Lee \& Gelembiuk 2008). Many studies have identified cases of rapid phenotypic changes in introduced populations (e.g. Losos et al. 1997; Stockwell \& Weeks 1999; Kristjánsson et al. 2002; Yonekura et al. 2007; Dlugosch \& Parker 2008; Kooyers \& Olsen 2012; Adachi et al. 2012; Rollins et al. 2015). However, it is often unclear whether these phenotypic changes result from natural selection or from other mechanisms such as genetic drift or admixture (Colautti \& Lau 2015). Indeed, genetic drift can lead to non-adaptive phenotypic changes. Admixture can generate new genotypic combinations and potentially new phenotypes that can differ in fitness from parental forms in the new local conditions. Therefore, in addition to predicting invasive potential, documenting the invasion history and the genetic structure of invasive populations should give insights on the roles of neutral processes in phenotypic changes that can be observed in these populations (Gonzalez-Quevedo et al. 2015).

The Red-whiskered Bulbul (Pycnonotus jocosus, Carolus Linnaeus, 1758) is a popular cage bird native to South-eastern Asia (Peters 1960; Clergeau \& MandonDalger 2001). It has been introduced to and successfully invaded many tropical and subtropical regions all over the world, mainly during the 1960s and 1970s (Lever 2010): the South-Eastern coast of Australia (New South Wales and South Australia), the United States (California, Florida and Hawaii), and several islands of the Indian Ocean (Comoros, Mauritius, Reunion Island and Seychelles). Population size increased very rapidly in all these locations (Carleton \& Owre 1975; Williams \& Giddings 1984; Clergeau \& Mandon-Dalger 2001) even though the environments are quite diverse in terms of biotic and abiotic conditions, suggesting that this species is able to adapt rapidly to new ecological conditions. The Red-whiskered bulbul is considered a pest in a part of its invasive range due to the damages it causes to orchards (Williams \& Giddings 1984; Mandon-Dalger et al. 2004; Lever 2010) and its negative impacts on the invaded ecosystems where it can compete with, or predate on, endemic species (Lever 2010; Linnebjerg et al. 2010), serve as a reservoir for parasites affecting local fauna (Shehata et al. 2001), or facilitate the dispersal of seeds of invasive plants (Carleton \& Owre 1975; Mandon-Dalger et al. 2004; Linnebjerg et al. 2010). Despite 
these impacts, the only information available on invasive populations is generally the date of first introduction or first observation.

Rapid phenotypic changes have been previously reported in an invasive population of Red-whiskered bulbul. Amiot et al. (2007) showed that in Reunion Island, individuals inhabiting opposite coasts have distinct morphologies. These two coasts present contrasting ecological conditions: the coast exposed to the prevailing wind (windward) is more humid and densely forested than the opposite coast (leeward). Historical sources suggest that the Redwhiskered bulbul was introduced only once on Reunion from Mauritius in 1972 at the south-eastern point of the island (Saint Philippe) and colonized both coasts from this point (Clergeau \& Mandon-Dalger 2001; Lever 2010). Considering the reproductive success and rapid spread of this species on Reunion, Amiot et al. (2007) hypothesized that rapid local adaptation could explain the morphological differences observed between the windward and leeward coasts, and thus the invasive success of the Red-whiskered bulbul on Reunion. In addition, the two coasts are separated by a high mountain range which is thought to constitute an obstacle to the dispersal of Red-whiskered bulbuls, isolating the two populations, and might thus facilitate local adaptation (Amiot et al. 2007). However, some Red-whiskered bulbuls were observed at the opposite position from the known introduction point (Sainte Marie) in 1978, long before the population introduced in Saint Philippe could have reached this location by natural colonization as it only started to spread in the surroundings of St Philippe in 1980 (Clergeau \& MandonDalger 2001). This suggests that bulbuls were transported by humans across Reunion or that unknown introduction events took place. With such an uncertain historical context it is not possible to exclude the possibility that the phenotypic differences described by Amiot et al. (2007) result from the invasion history of the population rather than from natural selection.
In this article, we wanted to test the hypothesis that the morphological differences observed between the two coasts of Reunion are due to neutral evolutionary processes. We used three approaches to test this hypothesis. First, we studied the morphology of Red-whiskered bulbuls established in two other tropical islands very similar to Reunion in terms of size, geography and climate: Mauritius and Oahu (Hawaii). Like Reunion, these two islands are divided by a mountain range and have a windward coast and a leeward coast. Redwhiskered bulbuls are common birds in these three islands. Historical sources suggest that the Red-whiskered bulbul was introduced on Mauritius, probably from India, in 1892, whereas Oahu was colonized approximately at the same period as Reunion (1965) but from an unknown source (Lever 2010). We predicted that if the morphological differences observed between leeward and windward coasts of Reunion are adaptive, we would find the same morphological pattern on Mauritius and Oahu. On the contrary, if these morphological differences are due to neutral processes, we expected to find different morphological patterns on each island. Secondly, we investigated with molecular data the invasion history of Red-whiskered bulbuls established on these three islands. In particular, we used an approximate Bayesian computation approach widely used to reconstruct the invasion history of invasive species (e.g. Jackson et al. 2015; Jacquet et al. 2015; Rijal et al. 2015; Wei et al. 2015). We predicted that if multiple introductions from different origins, founder effects or genetic drift are the cause of the morphological patterns observed, we would find evidence of multiple introductions and a neutral genetic structure matching the morphological patterns observed. Finally, we compared the morphology of Redwhiskered bulbuls between the invasive populations and the source populations identified with molecular data. We predicted that if the morphological patterns found on the islands are due to neutral processes, each 
population would have diverged differently from its source population whereas if the morphological patterns are the result of adaptation to local conditions, all the populations experiencing similar conditions would have diverged towards a similar morphology.

\section{Material and methods \\ Samples}

Tissue samples and morphological data were collected from the whole native range of the Red-whiskered bulbul and from three invasive populations (Reunion, Mauritius and Oahu). Sampling live individuals from the whole native range was unrealistic considering it covers a very large region in
Asia. Instead toe-pads from 27 museum specimens covering evenly the whole native range and all recognized subspecies were obtained from the collections of several museums (figure $1 \mathrm{~b}$ and table $\mathrm{S} 1$ ). Morphological measurements and pictures were taken by the same person (ALG) on 191 adult specimens from the native range in the collection of the British Natural History Museum. For invasive populations, feathers and morphological data were collected on wild-caught individuals. Morphological measurements and pictures were taken by the same person (ALG) and only on adult individuals. In 2002 and 2003, about 400 Red-whiskered bulbuls were captured on Reunion Island during a control program

a)

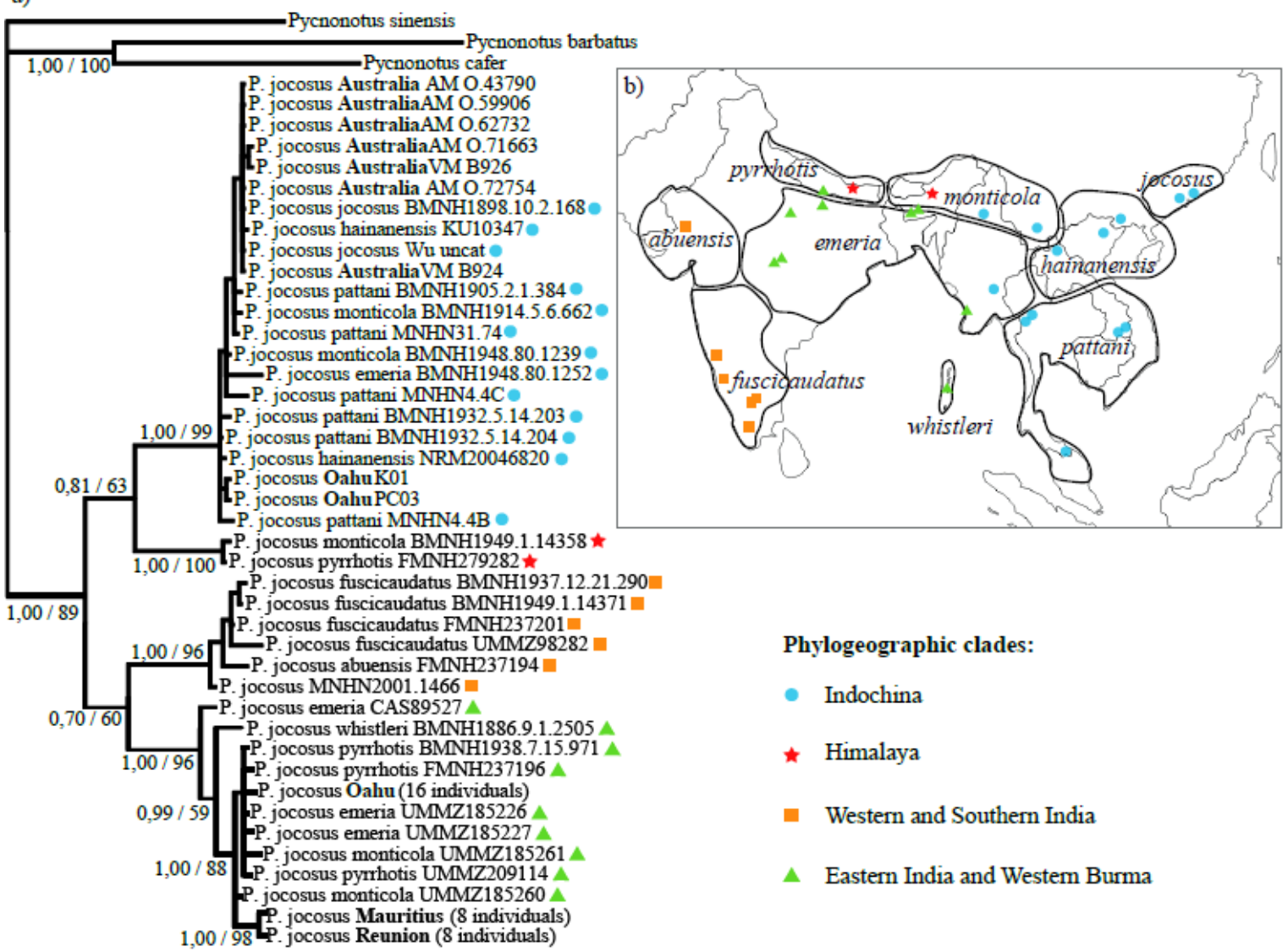

Fig. 1 Phylogeographic analysis based on the mitochondrial genes COI and ND2 sequenced in a sub-sample of individuals from the native range and invasive populations. a) Majority rule consensus tree obtained from the mixed-model Bayesian analysis of the concatenated dataset (COI and ND2). Support values indicated at the nodes are the posterior probability (threshold 0.50) and the bootstrap support (threshold 50\%) obtained from the maximum likelihood analysis, and the Bayesian approach respectively. b) Geographic distribution of the nine subspecies of Red-whiskered Bulbul in its native range as described in Peters (1960). Symbols show the geographic origin of the specimens used in the phylogeographic analysis. The color and form of the symbols indicate the phylogenetic clade to which they belong. 
organized by FDGDON (Fédération Départementale des Groupements de Défense contre les Organismes Nuisibles de la Réunion). They were captured in 12 sites spread along the windward and the leeward coasts (figure $3 b$ and table S2). In 2013, mist-nets were used to capture 50 adult Redwhiskered bulbuls on Mauritius and 45 on Oahu. On Mauritius, bulbuls were caught in three biological stations administrated by an NGO, the Mauritian Wildlife Foundation. One site was located on the windward coast (M-IA), one site was on the leeward side of the island (M-B) and the last one was in the mountain range delimiting the windward and leeward coasts but on the leeward side (M$\mathrm{C}$; figure $3 \mathrm{~b}$ and table S2). On Oahu, the bulbuls were caught in two sites, one on each coast (figure $3 \mathrm{~b}$ and table S2). Wild-caught individuals were sexed using the PCR-based protocol of Griffiths et al. (1998), whereas for museum specimens we relied on the information available on specimen labels.

\section{DNA extraction, amplification and sequencing}

In order to prevent contamination from modern samples, DNA extraction and PCR amplification from museum samples were conducted in a separate laboratory dedicated to ancient DNA work. In addition, equipment and benches were decontaminated before and after use by application of UV light and bleach. Finally, negative controls were added during amplifications. Total genomic DNA was extracted from toe-pads or feathers with the QIAamp DNA Micro Kit (Qiagen) following the manufacturer instructions for the blood and tissue samples. The digestion volume was doubled, with the final concentration of $2 \mathrm{mg} / \mathrm{mL}$ for Proteinase $\mathrm{K}$ and $50 \mathrm{mM}$ for dithiothreitol. For the phylogeographic analysis, a region was amplified in the two mitochondrial genes COI and ND2 (655 bp and 564 bp respectively). For the fresh tissue samples, the two genes were amplified in one fragment whereas in the case of museum samples, short overlapping fragments ( $c a$.
$200 \mathrm{bp}$ ) were amplified with internal primers (table S3). The amplification protocols are described in Appendix S1 of the Supporting Information. Positive PCR products were sequenced in both directions on an Applied Biosystems 3130XL DNA sequencer. The sequences were assembled in CODONCODE 4.0 (CODONCODE Corporation). For the population genetics study, ten polymorphic microsatellite loci were selected from the literature (table S4) and amplified following the protocol described in Appendix S2 of the Supporting Information. Samples were genotyped on an Applied Biosystems 3130XL DNA sequencer. Genotypes were scored with GeneMapper 4.0 (Applied Biosystems) and checked manually.

\section{Phylogeographic analysis}

In addition to the 27 museum specimens, the $\mathrm{COI}$ and ND2 sequences of three additional specimens from the native range were retrieved from Genbank (table S1). The COI and ND2 genes were also sequenced in a total of 34 individuals caught on both coasts in the three invaded islands: Reunion ( 8 individuals), Mauritius (8 individuals), and Oahu (18 individuals, table S1). Seven individuals from an invasive population located around Sydney (Australia) were also added to see whether there is only one source for all invasive populations worldwide (table S1). Finally, following the results of Moyle and Marks (2006), Pycnonotus sinensis, Pycnonotus barbatus and Pycnonotus cafer were selected as out-groups, and sequences for one individual of each species were retrieved from Genbank (table S1). The COI and ND2 genes were concatenated in a partitioned dataset analyzed under the Bayesian inference and the maximum likelihood criteria. These two procedures are described in Appendix S3 of the Supporting Information.

\section{Morphological data}

Traditional morphological measurements and geometric morphometric data were used to study the morphology of 191 individuals from the native range and more than 300 
individuals from invasive populations (Reunion: 231; Mauritius: 50; Oahu: 45). Five traditional measurements were recorded: beak length, beak width, beak depth, folded wing length and central tail feathers length. Log-shape ratios (Mosimann \& James 1979) were used in order to allow the study of morphological variables independent of size. Geometric morphometrics was used to describe more precisely the conformation of the beak (Zelditch et al. 2012). Pictures in lateral view of the beak of each individual were taken in standardized conditions. TPSDIG 2 (Rohlf 2010) was used to digitize four landmarks (anatomical points) and 20 sliding semi-landmarks (non-homologous points) from these pictures (figure S1, Gunz \& Mitteroecker (2013)). All pictures were digitized by the same person (ALG) and the repeatability of the digitization process was tested using a principal component analysis (PCA) on three repetitions taken on five specimens chosen randomly in the same subspecies (figure S2).

\section{Morphometric analyses}

Statistical analyses were done with R 2.15.3 (R Core Team 2013) and using the libraries ade4 (Thioulouse et al. 1997), Ape (Paradis et al. 2004), Hotelling (Curran 2006) and Rmorph (Baylac 2012). All the analyses were done separately for the traditional measurements taken on the whole body, and for geometric morphometric data on the beak. In order to assess if there are morphological differences between individuals with different origins, we defined two levels of geographic origin: the global geographic origin (the four regions defined by phylogeographic clade in the native range, Reunion, Mauritius, and Oahu), and nested into this variable, the sample sites where the individuals were captured.

Size- Analyses of covariance (ANCOVAs) were performed on body size and on beak size with global geographic origin and sample site as explanatory variables. Sex and the interactions between geographic groups and sex were added as co-factors. Tuckey's HSD post hoc tests were then used to test for pairwise differences between global geographic origins, sample sites and coasts within each island.

Conformation- PCAs were performed on the two data sets (whole body and beak) and the principal component axes representing 95\% of the total variance were kept as conformation variables for the following analyses. Before assessing an effect of origin on the conformation of individuals, we checked for differences in allometry between geographic groups using ANCOVAs performed for each conformation variable and for each data set with size, global geographic origin, sample site, sex and all possible interactions between them as explanatory factors. If some interactions between size and geographic groups were significant, the conformation variables were corrected for size by regressing size on it. Then, the effect of geographic groups on the conformation of individuals was assessed with multivariate analyses of covariance (MANCOVAs) performed for each data set, with conformation variables as response variables, and global geographic origin and sample site as explanatory variables. Sex and the interactions between geographic groups and sex were added as co-factors. Hotelling's T-squared post hoc tests were used to test for pairwise differences in conformation between global geographic origins, sample sites and coasts within each island. The threshold of acceptance of the null hypothesis was adjusted following the Bonferroni correction for global geographic origins and coasts, and following the Holm correction for sample sites (as the number of pairwise tests was elevated in the last case).

\section{Neutral genetic structure}

The ten microsatellite loci were amplified in a total of 480 individuals (Reunion: 385, Mauritius: 50 and Oahu 45). The presence of null alleles was assessed with FREENA (Chapuis \& Estoup 2007). Sample sites with fewer than 20 individuals were excluded 
from the analysis to increase its detection power. Mean number of alleles, Shannon's information index, observed heterozygosity, unbiased expected heterozygosity, and fixation index were assessed over all loci and for each sample site with GENEALEX 6.5 (Peakall \& Smouse 2012). Deviation from Hardy-Weinberg equilibrium and linkage disequilibrium between pairs of loci were tested for each sample site with GENEPOP 4.2.1 (Rousset 2008) using default parameter values.

Pairwise $\mathrm{F}_{\mathrm{ST}}$ values were calculated between all sample sites with FREENA (Chapuis \& Estoup 2007). The Bayesian clustering approach implemented in STRUCTURE 2.3.3 (Pritchard et al. 2000; Falush et al. 2003) was used to describe the genetic structure in the data set. Ten runs were performed for each value of $\mathrm{K}$ (number of clusters) from 1 to 17 (burn-in period: $1.10^{5}, 1.10^{6}$ iterations). The admixture model and the assumption of correlated allele frequencies were chosen.

\section{Isolation by distance and migration on Reunion Island}

In order to assess the causes of the genetic structure found on Reunion Island, isolation by distance (IBD) was investigated. The linearized genetic differentiation between each sampling site: Fst/(1-Fst), was used as genetic distance. Fst values were computed with FREENA $\left(1.10^{4}\right.$ permutations). Two kinds of geographic distances were used. First, the mountain range was not considered as an obstacle and the Euclidian distance between sites was used. Secondly, the mountain range was considered as an obstacle and the distances between sites were calculated following the coastline. In the first case, the distances were logtransformed as movements in two dimensions were considered. In the second case, the raw distances were used directly as only movements on one direction were considered (Rousset 1997). IBD between sample sites was tested first on the whole island, and then within the groups delimited by STRUCTURE. This approach allows to account for the effect of "by chance" geographic separation of groups that are also genetically differentiated (Perez et al. 2012). The P-values of the correlation coefficients were computed using a Mantel test $\left(1.10^{5}\right.$ permutations).

In addition, actual migration rates between the groups delimited by STRUCTURE were assessed with BAYESASS 1.3 (Wilson \& Rannala 2003). The parameters were chosen to fit with the author's recommendations: mixing parameters for allele frequencies: 0.12; inbreeding coefficients: 0.15 and migration rates: 0.07 ; number of iterations $=1.10^{7}$; burnin $=1.10^{6}$; sampling frequency: 100 . The sample site R-W2 was not used in this analysis as its individuals could not be confidently assigned to one of the two genetic clusters defined by STRUCTURE.

\section{Invasion scenarios}

The approximate Bayesian computation (ABC) method implemented in DIYABC 2.0.3 (Cornuet et al. 2008) was used on the microsatellite dataset to investigate the invasion history of the Red-whiskered bulbul in Reunion. This method can be used to compare potential invasion scenarios proposed by the user (Estoup \& Guillemaud 2010). We tested whether the two genetic clusters identified by STRUCTURE on Reunion $\left(R_{B}\right.$ and $\left.R_{O}\right)$ were founded by a single introduction event or independent ones. Four scenarios were compared. In the first two scenarios, a single introduction event happened on Reunion and the population then split in two (figure 4a, scenarios A and B). These two scenarios simulate the hypotheses of IBD or individuals transported by human within the island to explain the formation of the two clusters. In the two other scenarios, the two clusters were founded by independent introduction events from Mauritius (figure $4 a$, scenarios C and D). For each pair of scenarios, both possible orders for the foundation of the clusters were tested. Mauritius (M) was used as the source of all the introduction events on Reunion as 
historical data suggested that bulbuls were introduced to Reunion from there and as our molecular data (mitochondrial sequences and microsatellites) support this hypothesis. The priors for the demographic parameters were chosen according to historical and biological data available with ranges large enough to allow flexibility in the model (prior set 1, table S5). The microsatellite loci were separated in three groups according to their repeat motif. The mutation model parameters were left to default values following Gotzek et al. (2015). Within sample summary statistics used were means of number of alleles, genetic diversity, size variance and Garza-Williamson's $M$. Among samples summary statistics used were the means of the number of alleles, genetic diversity, size variance Fst values, shared allele distances and $(\mathrm{d} \mu)^{2}$ distances. For each scenario, one million data sets were simulated, and the posterior probability of each scenario was assessed using a polychotomous logistic regression on the $1 \%$ simulated data sets closest to the observed data set. The posterior distributions of demographic parameters were estimated under the most probable invasion scenario using a local linear regression on the $1 \%$ closest data sets. In order to evaluate the robustness of our inferences a second analysis was run with an alternative set of priors (prior set 2, table S5) and the posterior probabilities of all scenarios were estimated using the $0.1 \%$ and $1 \%$ closest simulated data sets for both sets of priors. The ability of the program to correctly choose the true scenario was evaluated by analyzing new data sets simulated from the different scenarios. For each scenario, 100 data sets were simulated using parameter values drawn from the prior set 1. Posterior probabilities of scenarios were estimated for each simulated test data set using the $1 \%$ closest data sets. These probabilities were used to compute type I and II errors in scenario choice. The data from the sample site R-W2 were not included in this analysis as the individuals could not be confidently assigned to one of the two genetic clusters defined by STRUCTURE.

Finally, the program BOTTLENECK 1.2 (Piry et al. 1999) was used to look for signatures of recent bottlenecks in the invasive populations of Oahu, Mauritius and Reunion $\left(\mathrm{R}_{\mathrm{O}}\right.$ and $\left.\mathrm{R}_{\mathrm{B}}\right)$. The two-phase model (TPM) was used with and a proportion of single-step mutations set to $70 \%$ with a variance of 30 among multiple steps. One tail Wilcoxon's signed rank tests were used to assess statistical significance of heterozygosity excess in each population.

\section{Results \\ Phylogeographic analysis}

The output of MrModelTest give the $\mathrm{HKY}+\Gamma$ and the GTR + I models as the best fit for the COI and ND2 genes, respectively. The phylogenetic analysis recovers four main clades (figure 1a). The four clades are coherent with the geographic origin of the specimens but match rather poorly with the current subspecies subdivision (figure 1b). The first clade contains the individuals from Western and Southern India (subspecies $P . j$. abuensis and fuscicaudatus). The second clade is composed of individuals from the lowlands of Eastern India to Western Burma (some but not all $P$. j. emeria, monticola and pyrrhotis) and Andaman Islands ( $P . j$. whistleri). The third clade is composed of individuals from the Himalayan region (some but not all $P$. j. monticola and pyrrhotis). Finally, the individuals from the Indochinese peninsula (South-eastern Burma, China, Laos, Malaysia, Thailand and Vietnam) fall together in a fourth group ( $P$. $j$. jocosus, hainanensis, pattani and some but not all emeria and monticola). All the individuals from Reunion and Mauritius share the same haplotype and fall in the Eastern Indian clade. The majority of Oahu individuals also share one haplotype and fall in the Eastern Indian clade. However, two individuals (out of 18) fall into the Indochinese clade. Finally, the individuals from Australia all belong to the Indochinese clade (figure 1a). 


\section{Morphometric analyses}

Size- Global geographic origin and sample site have a significant effect on size in the ANCOVAs performed on both data sets (table 1). Sex also has a significant effect on size (females are smaller and have a smaller beak than males, figures $\mathrm{S} 3 \mathrm{a}$ and $\mathrm{S} 4 \mathrm{a}$, table 1). For both data sets, post hoc tests show that 1) in most cases individuals from invasive populations are significantly different from the individuals of their source clade; and 2) there are significant differences in size between the three invasive populations (table 2, figures $\mathrm{S} 3 \mathrm{~b}$ and $\mathrm{S} 4 \mathrm{~b}$ ). There are also significant differences in size between some sample sites but not all in the whole body data set (figure S3c). In the beak data set, there are no significant differences in size between any pair of sample sites within each island (table S6, figure S4c).
When we compare the size of the individuals between the windward and leeward coasts, there are significant differences in body size between the coasts in the three islands and no differences in beak size (table 3 ).

Conformation- There are significant differences in allometry between geographic groups in the whole body data set (table S7). The morphological variables were therefore corrected for size in this data set. In the whole body data set, there is a significant effect of global geographic origin and sample site on conformation (table 1, figure $2 \mathrm{a}$ and c). Sex also has a significant effect on conformation but not the interactions between geographic groups and sex (table 1). In the beak data set, there is a significant effect of the triple interaction between sex, global geographic origin and sample site $\left(\mathrm{P}=1.95 .10^{-2}\right)$, therefore the MANCOVA

Table 1 Effect of geographic origin, sample site and sex on body size and beak size of the individuals (ANCOVAs, upper part of the table) and on body conformation and beak conformation of the individuals (MANCOVAs, lower part of the table).

\begin{tabular}{|c|c|c|c|c|}
\hline \multicolumn{2}{|l|}{ Size } & \multirow{2}{*}{$\frac{\text { Df }}{14,410}$} & \multirow{2}{*}{$\frac{\text { F value }}{0.77}$} & \multirow{2}{*}{$\frac{P \text { value }}{0.71}$} \\
\hline \multirow{5}{*}{$\begin{array}{l}\text { Whole } \\
\text { body }\end{array}$} & Geo.origin:Site:Sex & & & \\
\hline & Geo.origin:Sex & 6,424 & 0.49 & 0.82 \\
\hline & Geo.origin:Site & 14,430 & 6.59 & $3.759 \mathrm{e}-12^{*}$ \\
\hline & Geo.origin & 6,430 & 39.33 & $<2.20 \mathrm{e}-16^{*}$ \\
\hline & Sex & 1,430 & 80.45 & $<2.20 \mathrm{e}-16^{*}$ \\
\hline \multirow{5}{*}{ Beak } & Geo.origin:Site:Sex & 14,427 & 1.23 & 0.25 \\
\hline & Geo.origin:Sex & 6,441 & 0.33 & 0.92 \\
\hline & Geo.origin:Site & 14,447 & 3.25 & $6.06 \mathrm{e}-05^{*}$ \\
\hline & Geo.origin & 6,447 & 52.16 & $<2.20 \mathrm{e}-16^{*}$ \\
\hline & Sex & 1,447 & 41.56 & $2.96 \mathrm{e}-10^{*}$ \\
\hline \multicolumn{2}{|c|}{ Conformation } & Df & $\mathrm{F}$ value & $\mathrm{P}$ value \\
\hline \multirow{5}{*}{$\begin{array}{l}\text { Whole } \\
\text { body }\end{array}$} & Geo.origin:Site:Sex & 14,410 & 0.71 & 0.92 \\
\hline & Geo.origin:Sex & 6,424 & 0.71 & 0.80 \\
\hline & Geo.origin:Site & 14,430 & 2.69 & $5.23 \mathrm{e}-08^{*}$ \\
\hline & Geo.origin & 6,430 & 25.29 & $<2.20 \mathrm{e}-16^{*}$ \\
\hline & Sex & 1,430 & 58.69 & $<2.20 \mathrm{e}-16^{*}$ \\
\hline \multirow{2}{*}{$\begin{array}{c}\text { Beak } \\
\text { (Males) }\end{array}$} & Geo.origin:Site & 14,263 & 2.46 & $3.41 \mathrm{e}-08^{*}$ \\
\hline & Geo.origin & 6,263 & 9.13 & $<2.20 \mathrm{e}-16^{*}$ \\
\hline \multirow{2}{*}{$\begin{array}{c}\text { Beak } \\
\text { (Females) }\end{array}$} & Geo.origin:Site & 14,165 & 1.56 & $7.35 \mathrm{e}-03 *$ \\
\hline & Geo.origin & 6,165 & 7.63 & $<2.20 \mathrm{e}-16^{*}$ \\
\hline
\end{tabular}

* $\mathrm{P}$-values under the significance threshold. 
Table 2 Pairwise comparisons of body and beak size (Tuckey's HSD tests, upper part of the table) and pairwise comparisons of body and beak conformation (Hotelling's T-squared tests, lower part of the table) between the different geographic groups.

\begin{tabular}{|c|c|c|c|c|c|c|c|}
\hline Size & & $\begin{array}{c}\text { Western } \\
\text { India }\end{array}$ & Himalaya & Indochina & $\begin{array}{l}\text { Eastern } \\
\text { India }\end{array}$ & Reunion & Mauritius \\
\hline \multirow{6}{*}{ Whole body } & Himalaya & $\mathrm{x}$ & & & & & \\
\hline & Indochina & $<1.00 \mathrm{e}-05$ & $<1.00 \mathrm{e}-05$ & & & & \\
\hline & Eastern India & $\mathrm{x}$ & $\mathrm{x}$ & $<1.00 \mathrm{e}-05$ & & & \\
\hline & Reunion & $\mathrm{x}$ & $\mathrm{x}$ & $<1.00 \mathrm{e}-05$ & $\mathrm{x}$ & & \\
\hline & Mauritius & $<1.00 \mathrm{e}-05$ & $\mathrm{x}$ & $<1.00 \mathrm{e}-05$ & $<1.00 \mathrm{e}-05$ & $<1.00 \mathrm{e}-05$ & \\
\hline & Oahu & $2.64 \mathrm{e}-02$ & $1.94 \mathrm{e}-03$ & $\mathrm{x}$ & $4.50 \mathrm{e}-03$ & $<1.00 \mathrm{e}-05$ & $<1.00 \mathrm{e}-05$ \\
\hline \multirow{6}{*}{ Beak } & Himalaya & $\mathrm{x}$ & & & & & \\
\hline & Indochina & $2.81 \mathrm{e}-03$ & $2.85 \mathrm{e}-03$ & & & & \\
\hline & Eastern India & $\mathrm{x}$ & $\mathrm{x}$ & $1.92 \mathrm{e}-02$ & & & \\
\hline & Reunion & $<1.00 \mathrm{e}-05$ & $<1.00 \mathrm{e}-05$ & $6.23 \mathrm{e}-04$ & $<1.00 \mathrm{e}-05$ & & \\
\hline & Mauritius & $\mathrm{x}$ & $\mathrm{x}$ & $<1.00 \mathrm{e}-05$ & $1.02 \mathrm{e}-02$ & $<1.00 \mathrm{e}-05$ & \\
\hline & Oahu & $8.02 \mathrm{e}-03$ & $\mathrm{x}$ & $<1.00 \mathrm{e}-05$ & $1.36 \mathrm{e}-04$ & $<1.00 \mathrm{e}-05$ & $\mathrm{x}$ \\
\hline \multicolumn{2}{|l|}{ Conformation } & $\begin{array}{c}\text { Western } \\
\text { India }\end{array}$ & Himalaya & Indochina & $\begin{array}{c}\text { Eastern } \\
\text { India }\end{array}$ & Reunion & Mauritius \\
\hline \multirow{6}{*}{ Whole body } & Himalaya & $\mathrm{x}$ & & & & & \\
\hline & Indochina & $\mathrm{x}$ & $\mathrm{x}$ & & & & \\
\hline & Eastern India & $\mathrm{x}$ & $\mathrm{X}$ & $\mathrm{x}$ & & & \\
\hline & Reunion & 0.00 & $7.87 e-14$ & 0.00 & 0.00 & & \\
\hline & Mauritius & 0.00 & $1.52 \mathrm{e}-10$ & $2.12 \mathrm{e}-12$ & 0.00 & 0.00 & \\
\hline & Oahu & 0.00 & $3.37 \mathrm{e}-09$ & $1.30 \mathrm{e}-13$ & 0.00 & 0.00 & 0.52 \\
\hline \multirow{6}{*}{ Beak (males) } & Himalaya & $\mathrm{x}$ & & & & & \\
\hline & Indochina & $\mathrm{x}$ & $\mathrm{x}$ & & & & \\
\hline & Eastern India & $\mathrm{x}$ & $\mathrm{x}$ & $\mathrm{x}$ & & & \\
\hline & Reunion & $5.26 \mathrm{e}-11$ & $3.26 \mathrm{e}-06$ & 0.00 & $8.44 \mathrm{e}-15$ & & \\
\hline & Mauritius & $1.94 \mathrm{e}-05$ & $5.01 \mathrm{e}-04$ & $1.80 \mathrm{e}-09$ & $6.53 \mathrm{e}-07$ & $3.90 \mathrm{e}-05$ & \\
\hline & Oahu & $\mathrm{x}$ & $\mathrm{x}$ & $\mathrm{x}$ & $\mathrm{x}$ & $5.34 \mathrm{e}-08$ & $\mathrm{x}$ \\
\hline \multirow{6}{*}{$\begin{array}{c}\text { Beak } \\
\text { (females) }\end{array}$} & Himalaya & $\mathrm{x}$ & & & & & \\
\hline & Indochina & $\mathrm{x}$ & $\mathrm{X}$ & & & & \\
\hline & Eastern India & X & X & $\mathrm{X}$ & & & \\
\hline & Reunion & $8.60 \mathrm{e}-10$ & $2.90 \mathrm{e}-04$ & 0.00 & $1.15 \mathrm{e}-12$ & & \\
\hline & Mauritius & $\mathrm{x}$ & $\mathrm{x}$ & $1.05 \mathrm{e}-07$ & $3.18 \mathrm{e}-05$ & $2.99 \mathrm{e}-04$ & \\
\hline & Oahu & $\mathrm{X}$ & $\mathrm{X}$ & $5.23 \mathrm{e}-04$ & $\mathrm{X}$ & $6.26 \mathrm{e}-11$ & $3.24 \mathrm{e}-04$ \\
\hline
\end{tabular}

$\mathrm{x}$ : Non significant differences.

was performed separately for the two sexes. For both sexes, there is a significant effect of global geographic origin and sample site on conformation (table 1 , figure $2 \mathrm{~b}, \mathrm{~d}$ and $\mathrm{e}$ ). For both data sets, post hoc tests show that 1) the individuals from the three invasive populations have a conformation significantly different from their source clade (except in the case of females from Oahu for beak conformation); 2) when invasive populations are compared, Reunion is significantly different from Mauritius and Oahu and these last two populations are not significantly different (except in the case of 


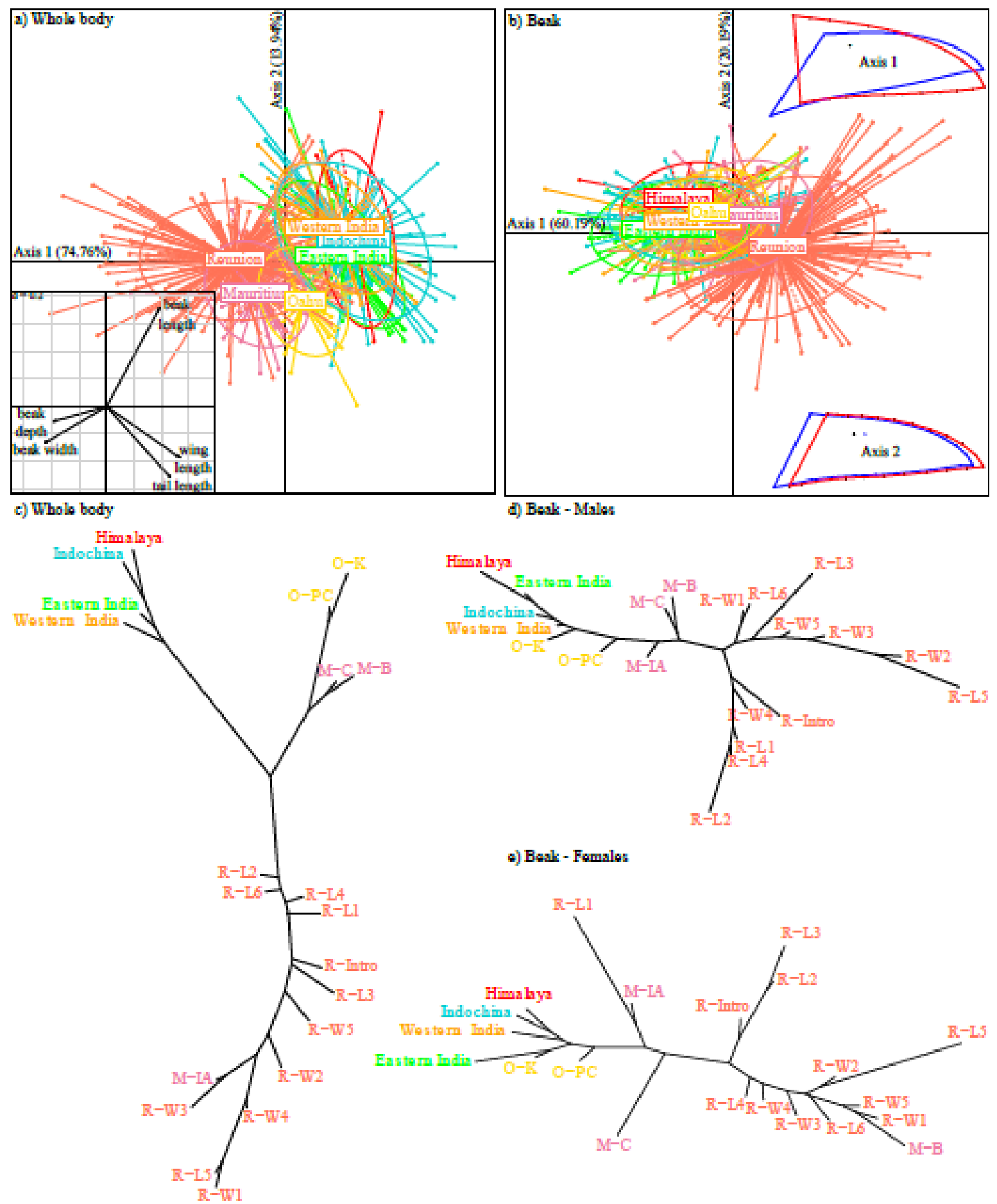

Fig. 2 Morphometric analyses based on traditional measurements and geometric morphometric data collected on the individuals from the native range and Mauritius, Reunion and Oahu. a) and b) Morphospaces defined by the first two axes of the PCAs on conformation variables. The correlation between the variables and the axes are represented for the PCA performed on the whole body data set (a). The extreme conformations associated with the axes are represented for the PCA performed on the beak data set (b, red conformation: positive end of the axis; blue conformation: negative end of the axis). c), d) and e): neighborjoining trees calculated with the Euclidian distance between the centroid of each sample site. Colors refer to the geographic location of individuals and sample sites. 
females for beak conformation; table 2, figure $2 \mathrm{a}$ and $\mathrm{b}$ ). Within islands, there are differences between some sample sites, but not all, in both data sets (figure $2 \mathrm{c}, \mathrm{d}$ and $\mathrm{e}$, table S8). When we compare the conformation of individuals between the windward and leeward coasts on each island, there are significant differences in conformation in Reunion and Mauritius in the whole body data set and also in Reunion in the beak data set but only for males (table 3). On Oahu, the two coasts are not significantly different in both data sets.

Table 3 Pairwise comparisons of body and beak size (Tuckey's HSD tests, upper part of the table) and pairwise comparisons of body and beak conformation (Hotelling's Tsquared tests, lower part of the table) between the windward and leeward coasts for each island.

\begin{tabular}{lcc} 
Data Set & Island & P-value \\
\hline Size & & \\
\hline \multirow{3}{*}{ Whole body } & Reunion & $0.00^{*}$ \\
& Mauritius & $4.10 \mathrm{e}-06^{*}$ \\
& Oahu & $4.35 \mathrm{e}-03^{*}$ \\
\hline \multirow{3}{*}{ Beak } & Reunion & $\mathrm{x}$ \\
& Mauritius & $\mathrm{x}$ \\
\hline Conformation & Oahu & $\mathrm{x}$ \\
\hline \multirow{3}{*}{ Whole body } & Reunion & $3.51 \mathrm{e}-05^{*}$ \\
& Mauritius & $1.78 \mathrm{e}-03^{*}$ \\
& Oahu & $\mathrm{x}$ \\
\hline \multirow{3}{*}{ Beak (males) } & Reunion & $5.22 \mathrm{e}-03^{*}$ \\
& Mauritius & $\mathrm{x}$ \\
& Oahu & $\mathrm{x}$ \\
\hline \multirow{3}{*}{ Beak (females) } & Reunion & $\mathrm{x}$ \\
& Mauritius & $\mathrm{x}$ \\
& Oahu & $\mathrm{x}$ \\
\hline
\end{tabular}

$\mathrm{x}$ : Non significant differences.

\section{Neutral genetic structure}

Amplification of the microsatellite loci was successful with only $1.8 \%$ of data missing over all loci and individuals. Null alleles were detected at locus TG05-046 with FREENA. The data from this locus were therefore not used. None of the sample sites significantly deviate from Hardy-Weinberg equilibrium nor present linkage disequilibrium (table 4). As expected in invasive populations the genetic diversity is not very high: the mean number of alleles per locus is usually between two and three and the observed and expected heterozygosity are under 0.50 (table 4). The genetic diversity is a little higher in Mauritius than in the two other islands (table 4). Genetic differentiation is low between the two sites in Oahu $\left(\mathrm{F}_{\mathrm{ST}}=0.04\right)$ and the three sites in Mauritius $\left(\mathrm{F}_{\mathrm{ST}} \leq 0.01\right)$. On Reunion Island, two groups of sites with low levels of differentiation $\left(\mathrm{F}_{\mathrm{ST}} \leq 0.02\right)$ can be distinguished: the sites R-W5, R-W4, R-W3 on one side and all the other sites in the other group (except the site R-W2 which is little differentiated compared to all the other sites on Reunion, table 5). When the sites of different islands are compared, Mauritius is less differentiated from Reunion than from Oahu (table 5).

The log likelihood of the simulations run with STRUCTURE increases sharply until $\mathrm{K}=4$, and starts decreasing afterwards, whereas the delta $\mathrm{K}$ presents a first peak at $\mathrm{K}=2$ and a second one at $\mathrm{K}=4$ (figure $\mathrm{S} 5$ ). For $\mathrm{K}=2$, the individuals from Reunion are separated into two clusters: the sites R-W3, $\mathrm{R}-\mathrm{W} 4$ and R-W5 (orange cluster, figure $3 \mathrm{a}$ ) and the other sites (blue cluster, figure $3 \mathrm{a}$ ). These clusters do not match with the windward and leeward coasts. Individuals from Oahu fall in the orange cluster whereas each individual from Mauritius is assigned to both clusters in approximately equal proportions. For $\mathrm{K}=4$, all individuals from Oahu are grouped in a single cluster as well as individuals from Mauritius. The individuals from Reunion are separated into the same two clusters obtained for $\mathrm{K}=2$ (figure $3 a$ and $b$ ).

\section{Isolation by distance and migration on Reunion Island}

When all sampled sites are considered, the correlation between genetic and geographic distances, whatever the type of distances, is 
Table 4 Genetic diversity at microsatellite loci in the invasive populations for each sampling site.

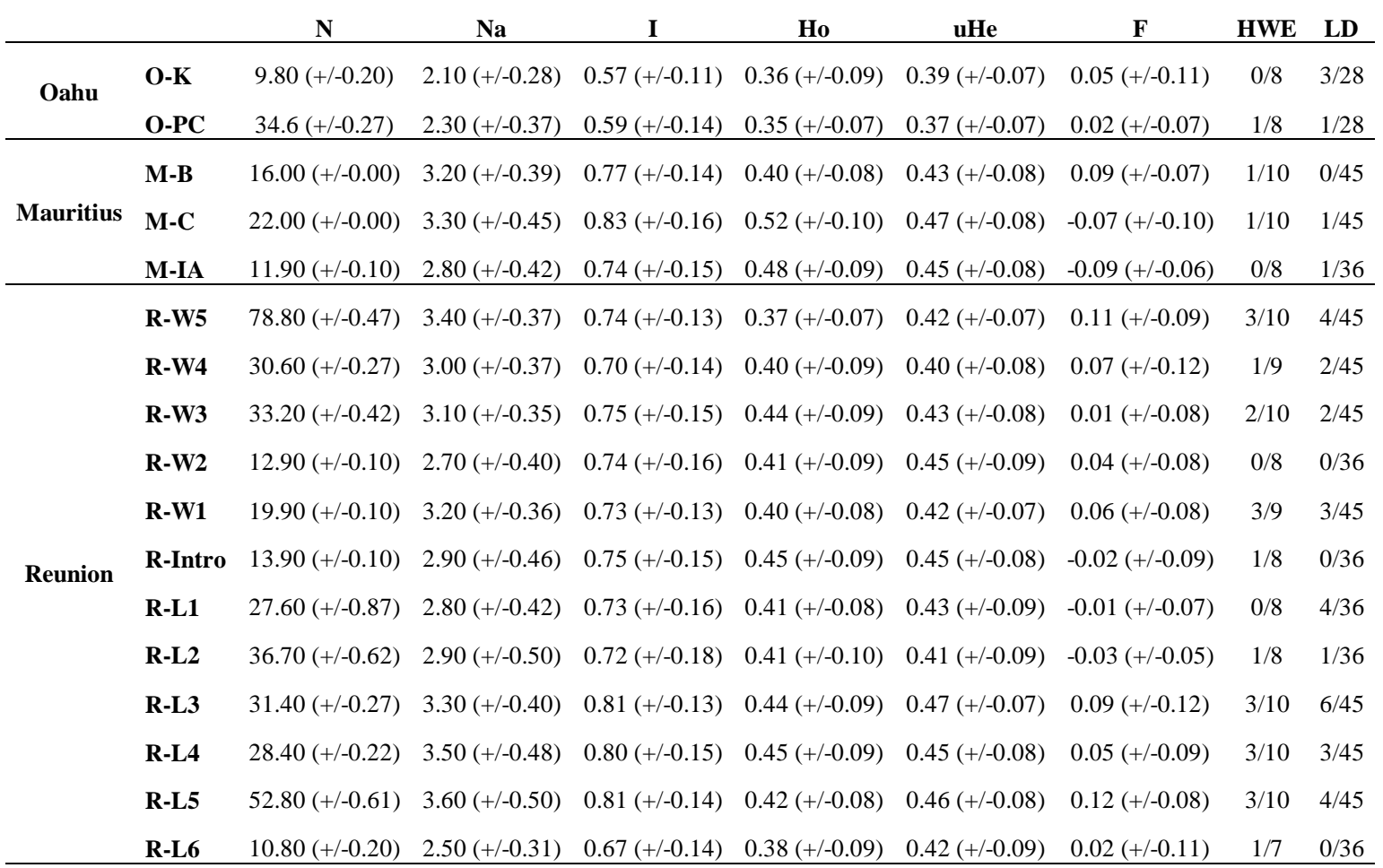

$\mathrm{N}$ : Mean number of individuals, Na: number of alleles, I: Shannon's diversity Index, Ho: observed heterozygosity, uHe: unbiased expected heterozygosity, and F: fixation index per sampling site and over all loci. HWE: proportion of loci deviating from Hardy-Weinberg equilibrium and LD: proportion of pair of loci showing linkage disequilibrium per sampling site.

Table 5 Pairwise $F_{S T}$ based on microsatellite loci between sample sites in invasive populations.

\begin{tabular}{|c|c|c|c|c|c|c|c|c|c|c|c|c|c|c|c|c|}
\hline Site & $\mathrm{O}-\mathrm{K}$ & O-PC & M-B & M-C & M-IA & R-W5 & R-W4 & R-W3 & R-W2 & R-W1 & R-Intro & R-L1 & R-L2 & R-L3 & R-L4 & R-L5 \\
\hline O-PC & 0.04 & & & & & & & & & & & & & & & \\
\hline M-B & 0.16 & 0.16 & & & & & & & & & & & & & & \\
\hline M-C & 0.17 & 0.17 & 0.01 & & & & & & & & & & & & & \\
\hline M-IA & 0.16 & 0.18 & 0.01 & 0.01 & & & & & & & & & & & & \\
\hline R-W5 & 0.13 & 0.11 & 0.08 & 0.07 & 0.07 & & & & & & & & & & & \\
\hline R-W4 & 0.16 & 0.11 & 0.08 & 0.06 & 0.08 & 0.01 & & & & & & & & & & \\
\hline R-W3 & 0.12 & 0.09 & 0.03 & 0.04 & 0.04 & 0.02 & 0.01 & & & & & & & & & \\
\hline R-W2 & 0.14 & 0.13 & 0.02 & 0.03 & 0.02 & 0.04 & 0.04 & 0.00 & & & & & & & & \\
\hline R-W1 & 0.20 & 0.22 & 0.14 & 0.13 & 0.11 & 0.18 & 0.16 & 0.13 & 0.06 & & & & & & & \\
\hline R-Intro & 0.21 & 0.21 & 0.11 & 0.11 & 0.11 & 0.15 & 0.14 & 0.11 & 0.05 & 0.01 & & & & & & \\
\hline R-L1 & 0.18 & 0.17 & 0.06 & 0.06 & 0.04 & 0.08 & 0.06 & 0.04 & 0.00 & 0.04 & 0.03 & & & & & \\
\hline R-L2 & 0.18 & 0.17 & 0.10 & 0.11 & 0.07 & 0.13 & 0.11 & 0.07 & 0.03 & 0.03 & 0.04 & 0.01 & & & & \\
\hline R-L3 & 0.17 & 0.20 & 0.10 & 0.10 & 0.07 & 0.14 & 0.12 & 0.10 & 0.05 & 0.00 & 0.02 & 0.04 & 0.02 & & & \\
\hline R-L4 & 0.17 & 0.19 & 0.10 & 0.10 & 0.06 & 0.14 & 0.13 & 0.10 & 0.04 & 0.00 & 0.01 & 0.02 & 0.01 & 0.00 & & \\
\hline R-L5 & 0.17 & 0.18 & 0.07 & 0.06 & 0.05 & 0.11 & 0.09 & 0.07 & 0.02 & 0.01 & 0.01 & 0.01 & 0.02 & 0.00 & 0.00 & \\
\hline R-L6 & 0.21 & 0.20 & 0.09 & 0.08 & 0.06 & 0.14 & 0.10 & 0.08 & 0.03 & 0.00 & 0.01 & 0.00 & 0.00 & 0.01 & 0.00 & 0.00 \\
\hline
\end{tabular}


a)
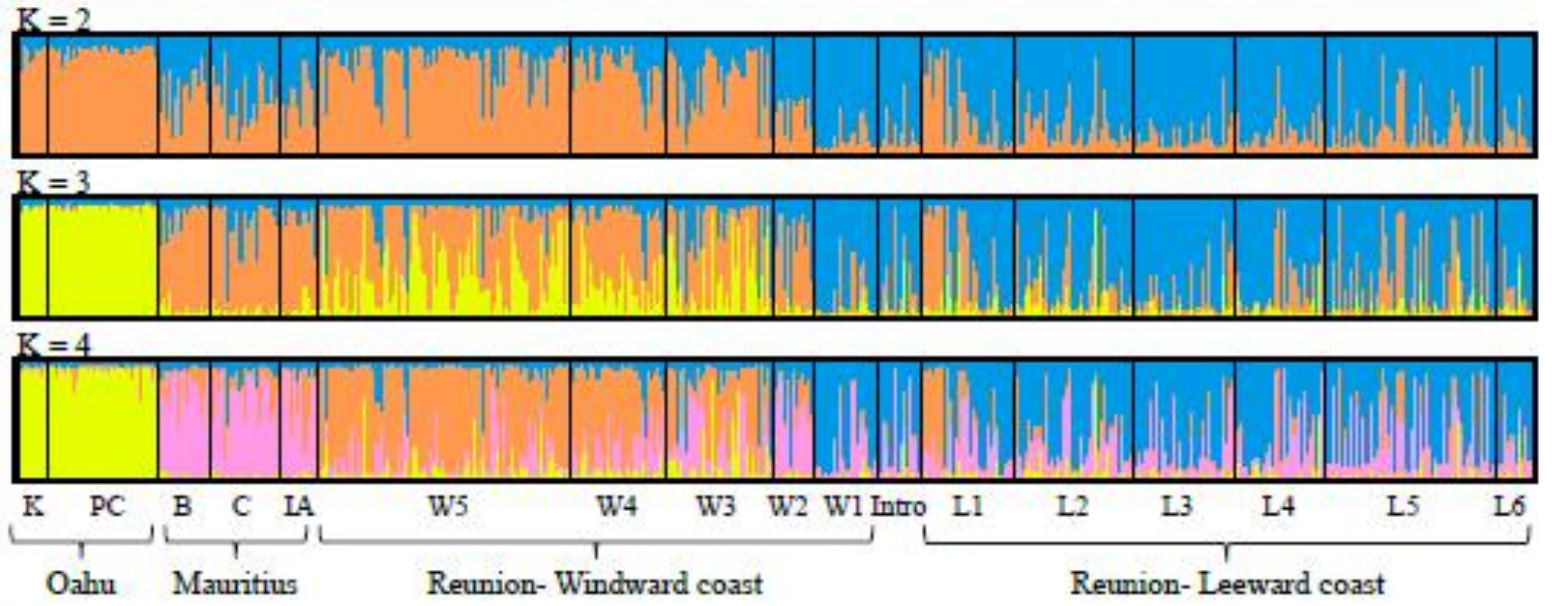

b)
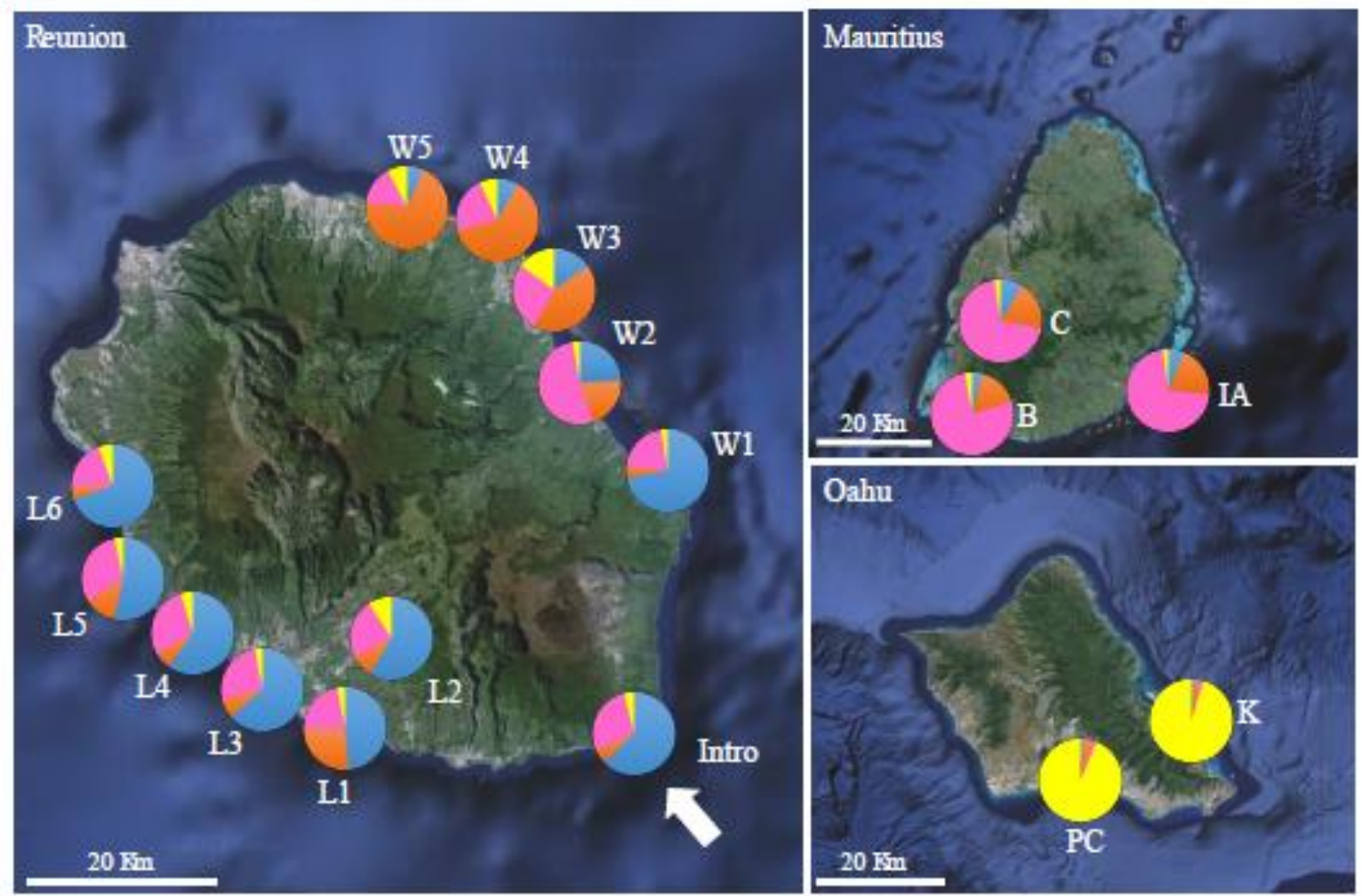

Fig. 3 Neutral genetic structure in the invasive populations based on the STRCUTURE analysis of the microsatellite dataset. a) Cluster assignments of each individual obtained with STRUCTURE for a number of cluster (K) equal to 2, 3 and 4 . For each value of $K$ the results of the 10 runs were pooled together using CLUMPP (Jakobsson \& Rosenberg 2007). Each vertical line represents a single individual and individuals are grouped by sample sites and island. $b$ ) Average cluster assignments of individuals for each sample site calculated with CLUMPP in the case where for $\mathrm{K}=4$. The white arrow indicates the location of the introduction of Redwhiskered bulbuls on Reunion Island in 1972.

significant and positive (Mantel tests; Euclidian distances: $\mathrm{r}=0.41, \mathrm{P}=2.54 .10^{-3}$; coastline distances: $\mathrm{r}=0.46, \mathrm{P}=4.85 .10^{-3}$ ). However, within each genetic cluster, the correlation between genetic and geographic distances is not significant (Mantel tests; orange cluster: Euclidian distances $\mathrm{P}=0.33$, coastline distances $\mathrm{P}=0.33$; blue cluster: 
Euclidian distances $\mathrm{P}=0.31$, coastline distances $\mathrm{P}=0.47$, figure S6). Actual migration rates of $4 \%$ per generation from the orange to the blue cluster and $5 \%$ in the other way were estimated with BAYESAsS.

\section{Comparison of invasion scenarios}

The scenario with two independent introductions on Reunion (scenario C) was found to have the highest posterior probability. In this scenario, a first introduction formed the blue cluster and a second introduction later formed the orange cluster (figure $4 \mathrm{~b}$, table S9)). The $95 \%$ confidence interval shows that scenario $\mathrm{C}$ can be confidently discriminated from the three other ones (figure 4b). Similar results were obtained with the second set of priors (table S9). The probability to reject a true scenario is quite high (Type I error for scenario A: $0.52, \mathrm{~B}: 0.54, \mathrm{C}: 0.46$ and D: 0.36 ) but this is mainly caused by the fact that scenarios $\mathrm{A}$ and $\mathrm{B}$ and scenarios $\mathrm{C}$ and $\mathrm{D}$ are too similar to be well discriminated. The type I error drops when pair of scenarios are considered together (Type I error for scenario A \& B: 0.26 and C \& D: 0.15). The probability to accept a false scenario is around 0.15 (Type II error for scenario A: 0.14, B: 0.14, C: 0.17 and D: 0.18). The estimates of the demographic parameters for scenario $\mathrm{C}$ are coherent with historical data and support the hypothesis that both populations in Reunion experienced bottlenecks following their introduction. The bottleneck length was estimated to be 23 generations for the orange cluster and 31 for the blue cluster, and the effective population sizes during these bottlenecks were estimated to be 30 times lower than actual size for both clusters, table S10). The analysis of heterozygosity excess conducted with BOTTLENECK also detects the signature of a bottleneck in the blue population of Reunion $\left(\mathrm{P}=2.44 .10^{-2}\right)$ and in the populations of Oahu $\left(\mathrm{P}=3.91 .10^{-3}\right)$ and Mauritius $\left(\mathrm{P}=1.86 .10^{-2}\right)$, but not in the orange population of Reunion $\left(\mathrm{P}=1.02 .10^{-1}\right)$. a)

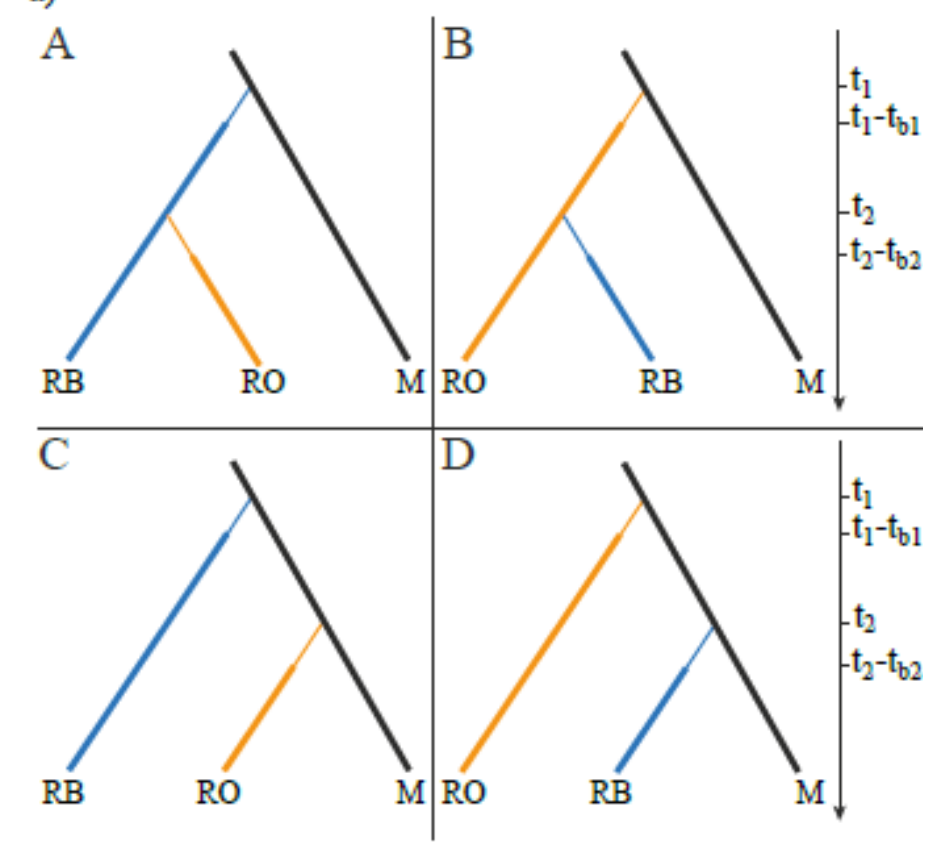

b)

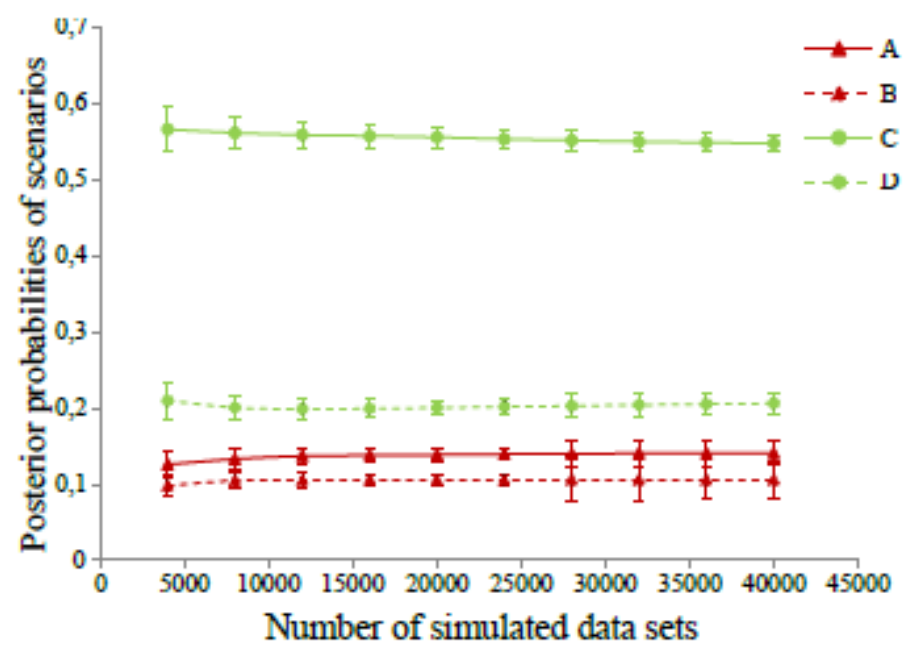

Fig. 4 Comparison of invasion scenarios conducted with DIYABC on the microsatellite dataset to infer invasion history on Reunion. a) Topologies of the four scenarios compared with DIYABC. M: Mauritius, $\mathrm{H}$ : Oahu, $\mathrm{R}_{\mathrm{B}}$ : Reunion blue cluster, $\mathrm{R}_{\mathrm{O}}$ : Reunion orange cluster. The thick lines represent population of constant size. The thin lines represent the duration of bottlenecks ( $b 1$ and $b 2$ ). The time scale is given on the right, $t_{1}$ and $t_{2}$ are the number of generations elapsed between the present and introduction events or splits, $t_{b 1}$ and $t_{b 2}$ represent the length of the bottlenecks b1 and b2 in number of generations. b) Posterior probabilities of the four scenarios calculated with the logistic regression approach implemented in DIYABC on the $1 \%$ closest data sets. Error bars represent $95 \%$ confidence intervals. 


\section{Discussion}

\section{Repeatability of morphological differences between island coasts}

Our morphological study shows significant differences in body and beak morphology between the two coasts of Reunion Island and thus confirms the results of Amiot et al. (2007). On average, individuals from the windward coast have shorter wings and tails than individuals of the same size from the leeward coast (figure S7). Wing and tail length can affect maneuverability and longdistance flight capacities. The differences we observed could thus reflect local adaptations to the different kind of vegetation present on each coast. These individuals also have a different beak conformation with wider, deeper and shorter beaks (figure S7), which could potentially result from differences in food items consumed (Grant 1965; Herrel et al. 2005). A stable isotope analysis conducted on the same individuals did not reveal clear diet differences between the two coasts of Reunion (Roussel et al. 2010). However, that kind of study would not detect differences between diets based on hard or soft seeds which could impact beak morphology. The individuals from the windward coast also have a larger body size than individuals from the leeward coast. Finally, more subtle differences were also detected in beak conformation with the geometric morphometric approach. Males and females are divided into several groups that do not exactly correspond to the two coasts suggesting that other factors than the environmental differences between island sides are affecting the conformation of the beak.

A morphological differentiation between the two coasts was also detected on Mauritius although only in the whole body dataset. Individuals from the windward side of Mauritius have a conformation close to the one found on the windward coast of Reunion, and those of the leeward side also have longer wings and tails and wider, deeper and shorter beak than in the windward side but this difference is more pronounced than in Reunion (figure S7). In addition, as in Reunion, the individuals from the windward side are larger than those of the leeward side. On Oahu, the individuals from the windward side are also larger than those from the leeward side. However, we did not detect significant differences in conformation between the individuals from the two coasts on this island.

In the three islands, we thus found that individuals on the windward side have a larger body size than those of the leeward side. This suggests that the difference in size between the two environments is adaptive, it could for example reflect an adaptation to different thermoregulation needs (Bergmann's rule). However, it could also result from plastic responses, for example a richer diet on windward coasts which are more humid and where fruits and insects could thus be more abundant. Concerning the conformation of the individuals, the fact that we find the same morphological pattern on Reunion and Mauritius indicates that the differences in body conformation we observed could be adaptive and driven by similar selective forces. The fact that we did not find this pattern on Oahu could be due to less marked differences in ecological conditions between the two sides of Oahu than in Reunion and Mauritius. Alternatively, the population on Oahu might lack the evolutionary potential to adapt to the different environments. Indeed, we found that the genetic diversity is lower on Oahu than on the two other islands. In conclusion we found a repeatable difference in body size between windward and leeward coasts which suggests that body size evolution on each type of coast is adaptive and driven by selective forces that are common to the three islands. The differences in conformation between coasts were also similar on Reunion and Mauritius suggesting again an adaptive evolution of morphology associated to the type of coast although this was not observed on Oahu. 


\section{Repeatability of morphological divergence from source populations}

Based on mitochondrial sequences, the Redwhiskered bulbul can be divided into four main clades corresponding to four distinct geographic areas of its native range. Our phylogenetic analysis shows that the population introduced on Mauritius is native to a region embracing Eastern India and Western Burma. Our analysis also supports the historical data reporting that the populations of Reunion come from Mauritius as the individuals from both islands have similar haplotypes and are also close at neutral loci. On Oahu two distinct haplotypes from different geographic clades coexist (Eastern India/Western Burma and Indochinese peninsula) suggesting multiple introduction events, but it is possible that all individuals introduced on Oahu come from a region where both genetic clades co-exist (e.g. Myanmar). If several introductions took place, the Indochinese origin seems less important as this haplotype was found only in two individuals out of 18 . We did not find evidence for a double origin in our microsatellite data set. However, admixture between individuals from different origins is not always detected in both mitochondrial and nuclear sequences (Bradbury et al. 2015; Patten et al. 2015). In conclusion we can say that the population of Oahu originates from the same broad geographic region as the population of Mauritius but might also have in lesser proportions some origins in the Indochinese peninsula.

The sizes of the individuals and their beak have diverged between invasive populations and their source in the native range but this divergence is not the same for the three invasive populations. For body size, individuals from Reunion are not significantly different from those from Eastern India (and smaller than those from Mauritius); the individuals from Mauritius are larger than those from Eastern India; and the individuals from Oahu are larger than those from Eastern India but not significantly different from those from Indochina. Concerning beak size, the individuals from Reunion have a smaller beak than those from Eastern India (and Mauritius); and the individuals from Mauritius and Oahu have a bigger beak than those from Eastern India and Indochina. This inconsistency in body size and beak size divergence suggests that either the divergence in size is not due to natural selection or that the selective forces acting on body and beak size are different on each island although their geography, climate and vegetation seem very similar.

Conversely, the body and beak conformations of the individuals from all the invasive populations are significantly different from the conformation of individuals from the native range (except for beak conformation on Oahu). In addition, the three invasive populations have diverged in a similar direction from the native range: toward shorter wings and tails and shorter, wider and deeper beaks (figure 2). This suggests that common selective forces are acting on the phenotypes of the three invasive populations and could indicate adaptation to insular ecological conditions (Grant 1965). This adaptation can result from natural selection and/or phenotypic plasticity. Complementary approaches such as common garden experiments, reciprocal transplants or the study of evolution in genes associated with morphology would give further insight into the role of natural selection and phenotypic plasticity in the morphological changes we observed, and whether they are adaptive (Merilä \& Hendry 2014).

\section{Neutral genetic structure, invasion history and morphological changes}

On Mauritius and Oahu, we did not detect a neutral genetic structure. The differences we observed in body size and conformation between the two coasts of Mauritius and in body size between the two coasts of Oahu cannot therefore be explained by random processes and neutral evolution, otherwise one would expect to see differences in neutral loci between groups that are morphologically distinct. In the case of 
Mauritius and Oahu, morphological differentiations between coasts are therefore due either to natural selection and/or phenotypic plasticity.

On Reunion, there is a neutral genetic structure with two genetic clusters: one located on the Northern half of the windward coast and the other occupying the rest of the island. Isolation by distance is unlikely to explain this structure as we did not detect it in any cluster even in the blue cluster which embraces the largest part of the island, and as we found evidence for migration between the two clusters. Conversely, the comparison of invasion scenarios supports the hypothesis that the two clusters result from independent introduction events. Signatures of bottlenecks were detected both by the ABC approach and the analysis of heterozygosity excess in the blue cluster and by the ABC approach in the orange cluster. The genetic structure on Reunion is therefore probably due to founder effects rather than in situ isolation and subsequent drift. These founder effects could also explain the differences in morphology found between the two coasts of Reunion. However, the neutral genetic structure does not exactly match with the morphological pattern which is more complex. When body conformation is compared between sites, the sites of each coast are more or less similar between themselves and different from the sites of the other coast (except for R-L5, figure 2c). This is also true for body size (figure S3). For beak conformation, two groups of sites are detected in both males and females but they do not match the coasts or the neutral genetic clusters (figure $2 \mathrm{~d}$ and e). It is thus possible that several combined mechanisms (i.e. neutral processes, natural selection and/or phenotypic plasticity) are responsible for the morphological patterns observed on Reunion.

Finally, concerning the morphological divergence between invasive populations and their sources, the analysis of the microsatellite data shows that genetic diversity is not very high in the populations of the three islands and that they are genetically distinguishable even if they come from the same region of the native range. In addition, a striking lack of genetic diversity is also observed at the mitochondrial loci (one shared haplotype on Reunion and Mauritius, and two haplotypes on Oahu). Finally signatures of bottlenecks were detected in each invasive population (although not by the heterozygosity excess analysis for the orange cluster on Reunion). This suggests impacts of founder effects and bottlenecks on the genetic diversity of the invasive populations which could explain a part of the morphological divergence we observed between the invasive populations and their sources. In conclusion, neutral evolution can be confidently excluded as a factor explaining the morphological differentiations observed between the windward and leeward coast on Mauritius and Oahu. Conversely, it is possible that it explains, at least in part, the morphological differentiation observed between coast on Reunion, and the morphological divergence observed between the invasive populations and the native range.

\section{Conclusion}

Phenotypic changes in natural populations, and especially in invasive populations, can stem from different causes such as founder effects, drift, admixture, natural selection even on very short time scales, and phenotypic plasticity. In this article we show that it is necessary to study the historical context in which such phenotypic changes happen to understand the mechanisms involved and especially the role of neutral processes in these changes. Using this approach in the case of the invasive Redwhiskered bulbul, we were able to rule out the hypothesis of neutral evolution to explain phenotypic differences between windward and leeward coasts on Mauritius and Oahu whereas we showed that neutral evolution can explain, at least in part, phenotypic differences between coasts on Reunion and morphological divergence between invasive populations and their sources. Our comparative morphological 
study was complementary to this approach as it showed that body size and conformation differences between coasts on the three islands as well as divergence in conformation between invasive populations and their native ranges were repeated and thus likely due to adaptive processes. By combining these two approaches we can conclude that both neutral and rapid adaptive processes shaped the morphological divergence between invasive populations and their sources as well as the morphological differences between coasts on Reunion whereas rapid adaptive processes alone are responsible for the morphological differences between coasts on Mauritius and Oahu. Precise knowledge of the causes of phenotypic changes can be useful in the elaboration of control strategies for invasive species introduced in new environments or of conservation strategies for endangered species facing changes in their environment (Santamaría \& Méndez 2012). On the other hand, incomplete knowledge can lead to inadequate strategies and have dramatic consequences in both cases. This is why we argue that the role of neutral evolutionary processes should always be assessed alongside other evolutionary forces.

\section{Acknowledgements}

We thank the LabEx BCDiv and the ATM "Formes possibles, Formes réalisées Exploration du vivant" which financed our field missions and molecular analyses. We thank the British Natural History Museum for giving us access to their collection of Red-whiskered bulbuls. We thank the Australian Museum, the British Natural History Museum, the California Academy of Sciences, the Field Museum of Natural History, the Muséum National d'Histoire Naturelle, the University of Michigan Museum of Zoology and the Victoria Museum, for the samples they lent us. We also thank Frederic Austerlitz, Paul Verdu and Arnaud Estoup for their advice on $\mathrm{ABC}$ analyses. Finally, we thank the molecular systematic platform (SSM) of the Muséum National d'Histoire Naturelle, its staff, and particularly Josie Lambourdière, which was of great support for the setting up of microsatellites amplification protocols and for genotyping.

\section{Data Accessibility}

The morphometric and microsatellite data supporting this manuscript are archived in Dryad (doi:10.5061/dryad.563n9). The DNA sequences have been deposited in GenBank (see table S1 for access numbers).

\section{Author Contributions}

All authors participated in the writing of this manuscript. ALG collected all the data, with the help of BM for Oahu. ALG did the phylogeographic analysis with the help of DZ, the morphometric analyses with the help of RC, and the population genetic analyses. PC and SS supervised this study.

\section{References}

Adachi T, Ishikawa A, Mori S et al. (2012) Shifts in morphology and diet of non-native sticklebacks introduced into Japanese crater lakes. Ecology and Evolution, 2, 1083-1098.

Amiot C, Lorvelec O, Mandon-Dalger I et al. (2007) Rapid morphological divergence of introduced Red-whiskered Bulbuls Pycnonotus jocosus in contrasting environments. Ibis, 149, 482-489.

Bacigalupe LD (2008) Biological invasions and phenotypic evolution: a quantitative genetic perspective. Biological Invasions, 11, 2243-2250.

Baylac M (2012) Rmorph: A "R" Geometric Multivariate Morphometrics Library; baylac@mnhn.fr. 
Blackburn TM, Lockwood JL, Cassey P (2015) The influence of numbers on invasion success. Molecular Ecology, 24, 1942-1953.

Bradbury IR, Hamilton LC, Dempson JB et al. (2015) Transatlantic secondary contact in Atlantic Salmon, comparing microsatellites, a single nucleotide polymorphism array and restriction-site associated DNA sequencing for the resolution of complex spatial structure. Molecular Ecology, 24, 5130-5144.

Carleton AR, Owre O (1975) The red-whiskered bulbul in Florida: 1960-71. The Auk, 92, 4057.

Chapuis M-P, Estoup A (2007) Microsatellite null alleles and estimation of population differentiation. Molecular biology and evolution, 24, 621-631.

Clegg SM, Degnan SM, Kikkawa J et al. (2002) Genetic consequences of sequential founder events by an island-colonizing bird. Proceedings of the National Academy of Sciences of the United States of America, 99, 8127-8132.

Clergeau P, Mandon-Dalger I (2001) Fast colonization of an introduced bird: the case of Pycnonotus jocosus on the Mascarene Islands. Biotropica, 542-546.

Colautti RI, Lau JA (2015) Contemporary evolution during invasion: evidence for differentiation, natural selection, and local adaptation. Molecular Ecology, 24, 1999-2017.

Cornuet J-M, Santos F, Beaumont MA et al. (2008) Inferring population history with DIY ABC: a user-friendly approach to approximate Bayesian computation. Bioinformatics, 24, $2713-2719$.

Curran JM (2006) R Package "Hotelling."

Dlugosch KM, Parker IM (2008) Founding events in species invasions: genetic variation, adaptive evolution, and the role of multiple introductions. Molecular Ecology, 17, 431449.

Estoup A, Guillemaud T (2010) Reconstructing routes of invasion using genetic data: why, how and so what? Molecular Ecology, 19, 4113-4130.

Falush D, Stephens M, Pritchard JK (2003) Inference of population structure using multilocus genotype data: linked loci and correlated allele frequencies. Genetics, 164, 1567-1587.

Gonzalez-Quevedo C, Spurgin LG, Illera JC, Richardson DS (2015) Drift, not selection, shapes toll-like receptor variation among oceanic island populations. Molecular Ecology, 24, 5852-5863.

Gotzek D, Axen HJ, Suarez AV., Helms Cahan S, Shoemaker D (2015) Global invasion history of the tropical fire ant: a stowaway on the first global trade routes. Molecular Ecology, 24, 374-388.

Grant PR (1965) The adaptive significance of some size trends in island birds. Evolution, 19, 355-367.

Griffiths R, Double M, Orr K, Dawson R (1998) A DNA test to sex most birds. Molecular Ecology, 7, 1071-1075.

Gunz P, Mitteroecker P (2013) Semilandmarks: a method for quantifying curves and surfaces. Hystrix, the Italian Journal of Mammalogy, 24.

Herrel A, Podos J, Huber SK, Hendry AP (2005) Bite performance and morphology in a population of Darwin's finches: implications for the evolution of beak shape. Functional Ecology, 19, 43-48.

Jackson H, Strubbe D, Tollington S et al. (2015) Ancestral origins and invasion pathways in a globally invasive bird correlate with climate and influences from bird trade. Molecular Ecology, 24, 4269-4285.

Jacquet S, Garros C, Lombaert E et al. (2015) Colonization of the Mediterranean Basin by the vector biting midge species Culicoides imicola: an old story. Molecular Ecology, 24, $5707-5725$. 
Jakobsson M, Rosenberg NA (2007) CLUMPP: a cluster matching and permutation program for dealing with label switching and multimodality in analysis of population structure. Bioinformatics, 23, 1801-1806.

Kolbe JJ, Larson A, Losos JB, de Queiroz K (2008) Admixture determines genetic diversity and population differentiation in the biological invasion of a lizard species. Biology letters, 4, 434-437.

Kooyers NJ, Olsen KM (2012) Rapid evolution of an adaptive cyanogenesis cline in introduced North American white clover (Trifolium repens L.). Molecular Ecology, 21, 2455-2468.

Kristjánsson BK, Skúlason S, Noakes DLG (2002) Rapid divergence in a recently isolated population of threespine stickleback (Gasterosteus aculeatus L.). Evolutionary Ecology Research, 4, 659-672.

Lee CE (2002) Evolutionary genetics of invasive species. Trends in Ecology \& Evolution, 5347, 9-11.

Lee CE, Gelembiuk GW (2008) Evolutionary origins of invasive populations. Evolutionary Applications, 1, 427-448.

Lever C (2010) Naturalised birds of the world (A \& C Black, Ed,). London.

Linnebjerg JF, Hansen DM, Bunbury N, Olesen JM (2010) Diet composition of the invasive red-whiskered bulbul Pycnonotus jocosus in Mauritius. Journal of Tropical Ecology, 26, 347-350.

Lockwood JL, Cassey P, Blackburn T (2005) The role of propagule pressure in explaining species invasions. Trends in Ecology \& Evolution, 20, 223-228.

Losos JB, Warheit KI, Schoener TW (1997) Adaptive differentiation following experimental island colonization in Anolis lizards. Nature, 387, 70-73.

Mandon-Dalger I, Clergeau P, Tassin J, Rivière J-N, Gatti S (2004) Relationships between alien plants and an alien bird species on Reunion Island. Journal of Tropical Ecology, 20, 635642.

Merilä J, Hendry AP (2014) Climate change, adaptation, and phenotypic plasticity: the problem and the evidence. Evolutionary Applications, 7, 1-14.

Mosimann J, James F (1979) New statistical methods for allometry with application to Florida red-winged blackbirds. Evolution, 33, 444-459.

Moyle RG, Marks BD (2006) Phylogenetic relationships of the bulbuls (Aves: Pycnonotidae) based on mitochondrial and nuclear DNA sequence data. Molecular phylogenetics and evolution, 40, 687-695.

Paradis E, Claude J, Strimmer K (2004) APE: Analyses of Phylogenetics and Evolution in R language. Bioinformatics, 20, 289-290.

Patten MM, Carioscia SA, Linnen CR (2015) Biased introgression of mitochondrial and nuclear genes: a comparison of diploid and haplodiploid systems. Molecular Ecology, 24, 52005210.

Peakall R, Smouse PE (2012) GenAlEx 6.5: genetic analysis in Excel. Population genetic software for teaching and research-an update. Bioinformatics, 28, 2537-2539.

Peischl S, Excoffier L (2015) Expansion load: recessive mutations and the role of standing genetic variation. Molecular Ecology, 24, 2084-2094.

Perez M, Leblois R, Livoreil B et al. (2012) Effects of landscape features and demographic history on the genetic structure of Testudo marginata populations in the southern Peloponnese and Sardinia. Biological Journal of the Linnean Society, 105, 591-606.

Peters JL (1960) Check-list of birds of the world - Volume IX (E Mayr, JC Greenway, Eds,). Harvard University Press, Cambridge.

Piry S, Luikart G, Cornuet JM (1999) BOTTLENECK: A computer program for detecting recent reductions in the effective population size using allele frequency data. Journal of Heredity, 90, 502-503. 
Pritchard JK, Stephens M, Donnelly P (2000) Inference of population structure using multilocus genotype data. Genetics, 155, 945-959.

R Core Team (2013) R: A language and environment for statistical computing. R Foundation for Statistical Computing, Vienna, Austria.

Rijal DP, Alm T, Jahodová Š, Stenøien HK, Alsos IG (2015) Reconstructing the invasion history of Heracleum persicum (Apiaceae) into Europe. Molecular Ecology, 5522-5543.

Rohlf FJ (2010) TPSDIG, version 2.16. Stony Brook, NY: SUNY: Department of Ecology and Evolution.

Rollins LA, Richardson MF, Shine R (2015) A genetic perspective on rapid evolution in cane toads (Rhinella marina). Molecular Ecology, 24, 2264-2276.

Roussel J-M, Le Quilliec P, Clergeau P (2010) Stable isotope analysis to examine possible dietmorphology relationships among Red-whiskered Bulbuls introduced on Réunion Island. Ostrich, 81, 129-133.

Rousset F (1997) Genetic differentiation and estimation of gene flow from F-statistics under isolation by distance. Genetics, 145, 1219-1228.

Rousset F (2008) Genepop'007: a complete re-implementation of the genepop software for Windows and Linux. Molecular ecology resources, 8, 103-106.

Roy D, Lucek K, Walter RP, Seehausen O (2015) Hybrid "superswarm" leads to rapid divergence and establishment of populations during a biological invasion. Molecular Ecology, 24, 5394-5411.

Santamaría L, Méndez PF (2012) Evolution in biodiversity policy - current gaps and future needs. Evolutionary Applications, 5, 202-218.

Shehata C, Freed L, Cann RL (2001) Changes in the native and introduced bird populations on O'ahu, infections diseases and species replacement. Studies in Avian Biology, 22, 264273.

Stockwell CA, Weeks SC (1999) Translocations and rapid evolutionary responses in recently established populations of western mosquitofish (Gambusia affinis). Animal Conservation, 2, 103-110.

Thioulouse J, Chessel D, Dolédec S, Olivier JM (1997) ADE-4: a multivariate analysis and graphical display software. Statistics and Computing, 7, 75-83.

Wei S-J, Cao L-J, Gong Y-J et al. (2015) Population genetic structure and approximate Bayesian computation analyses reveal the southern origin and northward dispersal of the oriental fruit moth Grapholita molesta (Lepidoptera: Tortricidae) in its native range. Molecular Ecology, 24, 4094-4111.

Williams RN, Giddings LV (1984) Differential range expansion and population growth of bulbuls in Hawaii. The Wilson Bulletin, 96, 647-655.

Wilson GA, Rannala B (2003) Bayesian inference of recent migration rates using multilocus genotypes. Genetics, 163, 1177-1191.

Yonekura R, Kawamura K, Uchii K (2007) A peculiar relationship between genetic diversity and adaptability in invasive exotic species: bluegill sunfish as a model species. Ecological Research, 22, 911-919.

Zelditch ML, Swiderski DL, Sheets HD (2012) Geometric morphometrics for biologists: a primer. Elsevier Academic Press, London, Waltham and San Diego. 


\section{Supplementary information}

Appendix S1 - Amplification of mitochondrial genes

The following reagent quantities were used to amplify the COI and ND2 genes in a single fragment (primers, table S3): $13.94 \mu \mathrm{L}$ of Milli-Q water, $2 \mu \mathrm{L}$ of polymerase buffer $10 \mathrm{x}$ (Qiagen), $1.5 \mu \mathrm{L}$ of $\mathrm{MgCl}_{2}$ (Qiagen, $25 \mathrm{mM}$ ), $1 \mu \mathrm{L}$ of Dimethyl sulfoxide (DMSO), $0.8 \mu \mathrm{L}$ of dNTPs mix $(1.7 \mathrm{mM}$ each), $0.32 \mu \mathrm{L}$ of each primer $(10 \mu \mathrm{M}), 0.12 \mu \mathrm{L}$ of DNA polymerase (Qiagen, Taq 5 units/ $\mu \mathrm{L}$ ). Cycling conditions: $94^{\circ} \mathrm{C}, 5$ min.; $\left(94^{\circ} \mathrm{C}, 40 \mathrm{sec} . ; 55^{\circ} \mathrm{C}, 40 \mathrm{sec} . ; 72^{\circ} \mathrm{C}\right.$, 60sec.) $\mathrm{x} 40$ cycles; $72^{\circ} \mathrm{C}, 5 \mathrm{~min}$.

For the amplification of short fragments (primers, table S3), illustra ${ }^{\mathrm{TM}}$ Hot Start Mixes (GE Healthcare) were used with the following reagent quantities: $19 \mu 1$ of Milli-Q water, $1 \mu \mathrm{L}$ of $\mathrm{MgCl}_{2}$ (Qiagen, $\left.25 \mathrm{mM}\right), 1 \mu \mathrm{L}$ of each primer $(10 \mu \mathrm{M})$. Cycling conditions: $94^{\circ} \mathrm{C}, 5 \mathrm{~min}$.; $\left(94^{\circ} \mathrm{C}\right.$, 40 sec.; $61^{\circ} \mathrm{C}, 40 \mathrm{sec}$.; $72^{\circ} \mathrm{C}, 60 \mathrm{sec}$.) x 4 cycles; $\left(94^{\circ} \mathrm{C}, 40 \mathrm{sec}\right.$; $59^{\circ} \mathrm{C}, 40 \mathrm{sec}$; $72^{\circ} \mathrm{C}, 60 \mathrm{sec}$.) x 4 cycles; $\left(94^{\circ} \mathrm{C}, 40 \mathrm{sec} . ; 57^{\circ} \mathrm{C}, 40\right.$ sec.; $72^{\circ} \mathrm{C}, 60 \mathrm{sec}$.) x 32 cycles; $72^{\circ} \mathrm{C}, 5 \mathrm{~min}$.

Appendix S2 - Amplification of microsatellite loci

The ten microsatellite loci were amplified for each individual in two separate multiplex and tagged with fluorescent forward primers (dyes: 6-FAM, VIC, NED, PET; Applied Biosystems, table S4). PCR amplifications were done using the following reagent quantities: $1.25 \mu \mathrm{L}$ of the primer mix ( $1 \mu \mathrm{M}$ of each primer and TE buffer), $4 \mu \mathrm{L}$ of RNase-free water (Qiagen), $6.25 \mu \mathrm{L}$ of 2x Type-it Multiplex PCR Master Mix (Qiagen) in a final volume of $11.5 \mu \mathrm{L}$. The following cycling conditions were used: $95^{\circ} \mathrm{C}, 5 \mathrm{~min}$.; $\left(95^{\circ} \mathrm{C}, 30 \mathrm{sec}\right.$.; $57^{\circ} \mathrm{C}, 90 \mathrm{sec}$.; $72^{\circ} \mathrm{C}, 30 \mathrm{sec}$.) x 25 cycles; $60^{\circ} \mathrm{C}, 30 \mathrm{~min}$.

\section{Appendix S3 - Phylogenetic analyses}

The Bayesian inference was conducted with MrBayes 3.1.2 (Ronquist \& Huelsenbeck 2003). In order to account for the potential differences in nucleotide substitution models between the data partitions corresponding to the two genes, a mixed model approach was implemented. MrModelTest 2.3 (Nylander 2004) and PAUP* (Swofford 2003) were used to obtain the models best fitting the data, according to the AIC criterion (Akaike 1974). Uniform interval priors were selected for the parameters, except for base frequencies, which were assigned a Dirichlet prior (Huelsenbeck \& Ronquist 2001). Two independent runs of four incrementally heated Metropolis-coupled MCMC chains were run for 10 million generations. Sampling was done every 1000 generations, yielding 20000 trees. The online version of AWTY (Nylander et al. 2008) was used to assess the convergence of the MCMC chains and to estimate the "burn-in" length (2000 trees). Maximum likelihood searches of the partitioned dataset were conducted with RAxML v. 7.0.3 (Stamatakis 2006) using a GTR $+\Gamma+\mathrm{I}$ model and a random starting tree. The $\alpha$-shape parameters, GTR-rates, and empirical base frequencies were estimated and optimized for each partition. Nodal support was estimated using 100 bootstrap replicates. 


\section{Supplementary tables}

Table S1: Information on the specimens used in the phylogeographic analysis: species, subspecies, origin, date of collection, Museum ID and Genbank access numbers for the regions of COI and ND2 used in the analysis.

\begin{tabular}{|c|c|c|c|c|c|c|c|}
\hline Species & Subspecies & Country & Locality & Date & ID Number & $\mathrm{COI}$ & ND2 \\
\hline P. jocosus & jocosus & China & Guangzhou & 1858 & BMNH 98.10.2.168 & KX529897 & KX529966 \\
\hline P. jocosus & whistleri & India & Andaman islands & 1873 & BMNH 86.9.1.2505 & KX529896 & KX529965 \\
\hline P. jocosus & pyrrhotis & Nepal & Tribeni (Terai) & 1935 & BMNH 1938.7.15.971 & KX529903 & KX529972 \\
\hline P. jocosus & fuscicaudatus & India & Kurumabapatti, Salem District & 1929 & BMNH 1949.1.14371 & KX529907 & KX529976 \\
\hline P. jocosus & fuscicaudatus & India & Kurumabapatti, Salem District & 1929 & BMNH 1937.12.21.290 & KX529902 & KX529971 \\
\hline P. jocosus & emeria & Myanmar & Thandaung, Toungoo District & 1940 & BMNH 1948.80.1252 & KX529905 & KX529974 \\
\hline P. jocosus & monticola & India & Charduar (plains) & 1938 & BMNH 1949.1.14358 & KX529906 & KX529975 \\
\hline P. jocosus & monticola & China & Yunnan & NA & BMNH 1914.5.6.662 & KX529899 & KX529968 \\
\hline P. jocosus & monticola & Myanmar & Mogok, Katha District & 1934 & BMNH 1948.80.1239 & KX529904 & KX529973 \\
\hline P. jocosus & pattani & Laos & Thateng & 1931 & BMNH 1932.5.14.203 & KX529900 & KX529969 \\
\hline P. jocosus & pattani & Laos & Thateng & 1931 & BMNH 1932.5.14.204 & KX529901 & KX529970 \\
\hline P. jocosus & pattani & Malaysia & Ban-sai-kau, Patani & NA & BMNH 1905.2.1.384 & KX529898 & KX529967 \\
\hline P. jocosus & pattani & Laos & Boun Tai & 2004 & MNHN 31-74 & KX529942 & KX530010 \\
\hline P. jocosus & pattani & Thaïlande & Umphang & 1996 & MNHN 04-4C & KX529941 & KX530009 \\
\hline P. jocosus & pattani & Thaïlande & Umphang & 1996 & MNHN 04-4B & KX529940 & KX530008 \\
\hline P. jocosus & NA & Inde & Tamil Nadu & NA & MNHN 2001-1466 & KX529943 & KX530011 \\
\hline P. jocosus & emeria & Myanmar & Rakhaine State, Gwa Township & 2000 & CAS 89527 & KX529908 & KX529977 \\
\hline P. jocosus & abuensis & India & Anadra, Rajasthan & 1948 & FMNH 237194 & KX529909 & KX529978 \\
\hline P. jocosus & fuscicaudatus & India & Kasaragod, Kerala & 1937 & FMNH 237201 & KX529911 & KX529980 \\
\hline P. jocosus & pyrrhotis & India & Nichlaul, Uttar Pradesh & 1947 & FMNH 237196 & KX529910 & KX529979 \\
\hline P. jocosus & pyrrhotis & Nepal & Hitaura (Hetauda) & 1967 & FMNH 279282 & KX529912 & KX529981 \\
\hline P. jocosus & emeria & India & Belwani-Kisli, Madhya Pradesh & 1946 & UMMZ 185226 & KX529953 & KX530021 \\
\hline P. jocosus & emeria & India & Belwani-Kisli, Madhya Pradesh & 1946 & UMMZ 185227 & KX529954 & KX530022 \\
\hline P. jocosus & fuscicaudatus & India & Londa, Karnataka & 1938 & UMMZ 98282 & KX529952 & KX530020 \\
\hline P. jocosus & pyrrhotis & India & Kanpur, Uttar Pradesh & 1954 & UMMZ 209114 & KX529957 & KX530025 \\
\hline P. jocosus & monticola & India & Agia, Assam & 1952 & UMMZ 185260 & KX529955 & KX530023 \\
\hline P. jocosus & monticola & India & Agia, Assam & 1952 & UMMZ 185261 & KX529956 & KX530024 \\
\hline P. jocosus & NA & France (Reunion) & Saint-Benoît & 2003 & Clergeau 17 & KX529944 & KX530012 \\
\hline P. jocosus & NA & France (Reunion) & Saint-Benoît & 2003 & Clergeau 18 & KX529945 & KX530013 \\
\hline P. jocosus & NA & France (Reunion) & Saint-Benoît & 2003 & Clergeau 19 & KX529946 & KX530014 \\
\hline P. jocosus & NA & France (Reunion) & Saint-Benoît & 2003 & Clergeau 20 & KX529947 & KX530015 \\
\hline P. jocosus & NA & France (Reunion) & Saint-Benoît & 2003 & Clergeau 21 & KX529948 & KX530016 \\
\hline P. jocosus & NA & France (Reunion) & Les Avirons & 2003 & Clergeau 155 & KX529949 & KX530017 \\
\hline P. jocosus & NA & France (Reunion) & Les Avirons & 2003 & Clergeau 159 & KX529950 & KX530018 \\
\hline P. jocosus & NA & France (Reunion) & Les Avirons & 2003 & Clergeau 167 & KX529951 & KX530019 \\
\hline P. jocosus & NA & Mauritius & Ile aux aigrettes & 2013 & Le Gros IA01 & KX529938 & KX530006 \\
\hline P. jocosus & NA & Mauritius & Ile aux aigrettes & 2013 & Le Gros IA02 & KX529939 & KX530007 \\
\hline P. jocosus & NA & Mauritius & Camp & 2013 & Le Gros C05 & KX529935 & KX530003 \\
\hline P. jocosus & NA & Mauritius & Camp & 2013 & Le Gros C06 & KX529936 & KX530004 \\
\hline P. jocosus & NA & Mauritius & Camp & 2013 & Le Gros C07 & KX529937 & KX530005 \\
\hline
\end{tabular}




\begin{tabular}{|c|c|c|c|c|c|c|c|}
\hline P. jocosus & NA & Mauritius & Bel Ombre & 2013 & Le Gros B07 & KX529932 & KX530000 \\
\hline P. jocosus & NA & Mauritius & Bel Ombre & 2013 & Le Gros B08 & KX529933 & KX530001 \\
\hline P. jocosus & NA & Mauritius & Bel Ombre & 2013 & Le Gros B09 & KX529934 & KX530002 \\
\hline P. jocosus & NA & USA (Hawaii) & Pearl City & 2013 & Le Gros PC01 & KX529924 & KX529992 \\
\hline P. jocosus & NA & USA (Hawaii) & Pearl City & 2013 & Le Gros PC02 & KX529925 & KX529993 \\
\hline P. jocosus & NA & USA (Hawaii) & Pearl City & 2013 & Le Gros PC03 & KX529926 & KX529994 \\
\hline P. jocosus & NA & USA (Hawaii) & Pearl City & 2013 & Le Gros PC04 & KX529927 & KX529995 \\
\hline P. jocosus & NA & USA (Hawaii) & Pearl City & 2013 & Le Gros PC07 & KX529928 & KX529996 \\
\hline P. jocosus & NA & USA (Hawaii) & Pearl City & 2013 & Le Gros PC08 & KX529929 & KX529997 \\
\hline P. jocosus & NA & USA (Hawaii) & Pearl City & 2013 & Le Gros PC09 & KX529930 & KX529998 \\
\hline P. jocosus & NA & USA (Hawaii) & Pearl City & 2013 & Le Gros PC10 & KX529931 & KX529999 \\
\hline P. jocosus & NA & USA (Hawaii) & Kailula & 2013 & Le Gros Ka01 & KX529923 & KX529991 \\
\hline P. jocosus & NA & USA (Hawaii) & Kaneohe & 2013 & Le Gros K01 & KX529914 & KX529982 \\
\hline P. jocosus & NA & USA (Hawaii) & Kaneohe & 2013 & Le Gros K02 & KX529915 & KX529983 \\
\hline P. jocosus & NA & USA (Hawaii) & Kaneohe & 2013 & Le Gros K03 & KX529916 & KX529984 \\
\hline P. jocosus & NA & USA (Hawaii) & Kaneohe & 2013 & Le Gros K04 & KX529917 & KX529985 \\
\hline P. jocosus & NA & USA (Hawaii) & Kaneohe & 2013 & Le Gros K05 & KX529918 & KX529986 \\
\hline P. jocosus & NA & USA (Hawaii) & Kaneohe & 2013 & Le Gros K06 & KX529919 & KX529987 \\
\hline P. jocosus & NA & USA (Hawaii) & Kaneohe & 2013 & Le Gros K07 & KX529920 & KX529988 \\
\hline P. jocosus & NA & USA (Hawaii) & Kaneohe & 2013 & Le Gros K08 & KX529921 & KX529989 \\
\hline P. jocosus & NA & USA (Hawaii) & Kaneohe & 2013 & Le Gros K09 & KX529922 & KX529990 \\
\hline P. jocosus & NA & Australia & NA & 2009 & AM 0.72754 & KX529895 & KX529964 \\
\hline P. jocosus & NA & Australia & New South Wales, Richmond & 2007 & AM 0.71663 & KX529894 & KX529963 \\
\hline P. jocosus & NA & Australia & New South Wales, Figtree & 1987 & AM 0.59906 & KX529892 & KX529961 \\
\hline P. jocosus & NA & Australia & New South Wales, Sydney & 1971 & AM 0.43790 & KX529891 & KX529960 \\
\hline P. jocosus & NA & Australia & New South Wales, Sydney & 1991 & AM 0.62732 & KX529893 & KX529962 \\
\hline P. jocosus & NA & Australia & New South Wales & 1985 & MV B926 & KX529959 & KX530027 \\
\hline P. jocosus & NA & Australia & New South Wales & 1985 & MV B924 & KX529958 & KX530026 \\
\hline P. jocosus & jocosus & China & Guangzhou market & NA & $\mathrm{Wu}$ & GU170351 & GU170352 \\
\hline P. jocosus & hainanensis & China & Shiwandashan National NP & NA & KU 10347 & NA & GU112670 \\
\hline P. jocosus & hainanensis & Vietnam & Hanoi market & 2004 & NRM 20046820 & KX529913 & GQ242077 \\
\hline \multicolumn{8}{|l|}{ Outgroup } \\
\hline P. sinensis & & & & & T5464 & HQ700433 & HQ700401 \\
\hline P. barbatus & & & & & USNM 630912 & JQ176056 & \\
\hline P. barbatus & & & & & MNHN 02-29 & & GQ369695 \\
\hline P. cafer & & & & & NA & & KJ455616 \\
\hline P. cafer & & & & & USNM 620456 & JQ176062 & \\
\hline
\end{tabular}


Table S2: Sample sites names and locations in Reunion, Mauritius and Oahu.

\begin{tabular}{lllll} 
Island & Site ID & Site Name & latitude & longitude \\
\hline \multirow{6}{*}{ Reunion } & R-W5 & Sainte-Suzanne & -20.91 & 55.60 \\
& R-W4 & Saint-André & -20.96 & 55.65 \\
& R-W3 & Bras-Panon & -21.01 & 55.69 \\
& R-W2 & Saint-Benoît & -21.04 & 55.72 \\
& R-W1 & Sainte-Rose & -21.13 & 55.79 \\
& R-Intro & Saint-Philippe & -21.36 & 55.76 \\
& R-L1 & Saint-Pierre & -21.33 & 55.47 \\
& R-L2 & Le Tampon & -21.29 & 55.52 \\
& R-L3 & Saint-Louis & -21.29 & 55.41 \\
& R-L4 & Etang-Salé & -21.27 & 55.36 \\
& R-L5 & Les Avirons & -21.24 & 55.33 \\
& R-L6 & Saint-Leu & -21.17 & 55.29 \\
\hline \multirow{4}{*}{ Mauritius } & M-B & Bel Ombre field station & -20.46 & 57.43 \\
& M-C & Camp field station & -20.39 & 57.45 \\
& M-IA & Ile aux aigrettes & -20.42 & 57.73 \\
\hline \multirow{2}{*}{ Oahu } & O-K & Kaneohe & 21.41 & -157.80 \\
& O-PC & Pearl city & 21.42 & -157.95 \\
\hline
\end{tabular}

Table S3: primers used for amplification of COI and ND2 genes.

\begin{tabular}{|c|c|c|c|c|}
\hline Gene & Primer F & & Primer R & \\
\hline COI (single fragment) & COI-ExtF & $\begin{array}{l}\text { ACGCTTTAACACTCAGCCAT } \\
\text { CTTACC }\end{array}$ & COI-BirdR1 & $\begin{array}{l}\text { ACGTGGGAGATAATTCCAAATC } \\
\text { CTG }\end{array}$ \\
\hline COI (1st fragment) & COI-ExtF1b & $\begin{array}{l}\text { GATGAYTATTTTCAACCAAC } \\
\text { CACAAAGA } \\
\text { TTGGCGGATTYGGAAACTG }\end{array}$ & COI-R220b & $\begin{array}{l}\text { CTYATGTTGTTTATTCGRGGGAA } \\
\text { AGC } \\
\text { TGTGATAGGGCKGGGGGTTTTA }\end{array}$ \\
\hline COI (2nd fragment) & COI-F167b & $\begin{array}{l}\text { GT } \\
\text { TCTCCTCAATCTTAGG }\end{array}$ & COI-R451b & $\begin{array}{l}\text { TGTT } \\
\text { GGTAGGATTAGGATATAGACTT }\end{array}$ \\
\hline COI (3rd fragment) & COI-F403b & $\begin{array}{l}\text { AGCAAT } \\
\text { AGCTATCGGGCCCATACCCC }\end{array}$ & COI-R661b & $\begin{array}{l}\text { CTGGATG } \\
\text { TTGAAGGCCTTCGGTTTAGGTG }\end{array}$ \\
\hline ND2 (single fragment) & ND2-ExtF & $\begin{array}{l}\text { GAA } \\
\text { AGCTATCGGGCCCATACCCC }\end{array}$ & ND2-ExtR & $\begin{array}{l}\text { A } \\
\text { TGTCCAGTGTACCATGCGTTGGT }\end{array}$ \\
\hline ND2 (1st fragment) & ND2-ExtF & $\begin{array}{l}\text { GAA } \\
\text { ACTTCTTGACCCAAGCAACA }\end{array}$ & ND2-R223 & $\begin{array}{l}\text { CA } \\
\text { GAATAGTAGCGTGATTGGGGGG }\end{array}$ \\
\hline ND2 (2nd fragment) & ND2-F175 & $\begin{array}{l}\text { GCCTCA } \\
\text { TGCAAGGATCCCCCCTTATy }\end{array}$ & ND2-R405 & $\begin{array}{l}\text { AATT } \\
\text { GGGGTTGTAGGTGATGATGATG }\end{array}$ \\
\hline ND2 (3rd fragment) & ND2-F355 & ACTGGA & ND2-R568 & GCTA \\
\hline
\end{tabular}


Table S4: Description of microsatellite markers used in the study: name, number of alleles found in our study, sequence of the primers used for amplification, type of motif according to the literature, fluorescent label used for the amplification and original reference.

\begin{tabular}{|c|c|c|c|c|c|}
\hline locus & $\mathbf{N a}$ & primers & motif & label & source \\
\hline \multirow[t]{2}{*}{ Pca3 } & 4 & F:GGTGTTTGTGAGCCGGGG & $(\mathrm{GT})_{6} \mathrm{CT}(\mathrm{GT})_{3}$ & 6-Fam & Dawson et al. (2000) \\
\hline & & R:TGTTACAACCAAAGCGGTCATTTG & & & \\
\hline \multirow[t]{2}{*}{ TG04-004 } & 2 & F:CTGGAGCAGTATTTATATTGATCTTCC & $(\mathrm{AT})_{10} \mathrm{GT}(\mathrm{AT})_{7}$ & Pet & Dawson et al. (2010) \\
\hline & & R:GAAGATGTGTTTCACAGCATAACTG & & & \\
\hline \multirow[t]{2}{*}{ Pfl35 } & 6 & F:GTGCAGTTTCGGTTGTTTCCC & $(\mathrm{TAGA})_{8}$ & Ned & Lokugalappatti et al. (2008) \\
\hline & & R:CCATGGTACTGTTAGAGATCGGTATC & & & \\
\hline \multirow[t]{2}{*}{ TG13-009 } & 3 & F:TGTGGTGGGATAGTGGACTG & $(\mathrm{AT})_{4} \mathrm{GT}(\mathrm{AT})_{5}$ & Vic & Dawson et al. (2010) \\
\hline & & R:CTGTAAAATGTGCAAGTAACAGAGC & & & \\
\hline \multirow[t]{2}{*}{ TG05-053 } & 4 & F:GCATCATCTGGTTGAACTCTC & $(\mathrm{T})_{4} \mathrm{GA}(\mathrm{T})_{6} \mathrm{AA}(\mathrm{T})_{16} \mathrm{AA}(\mathrm{T})_{4} \mathrm{G}(\mathrm{T})_{6}$ & 6-Fam & Dawson et al. (2010) \\
\hline & & R:ACCCTGTTTACAGTGAGGTGTT & & & \\
\hline \multirow[t]{2}{*}{ TG01-040 } & 3 & F:TGGCAATGGTGAGAAGTTTG & $(\mathrm{AT})_{2} \mathrm{G}(\mathrm{AT})_{7} \mathrm{AC}(\mathrm{AT})_{6} \mathrm{TT}(\mathrm{AT})_{2}$ & Pet & Dawson et al. (2010) \\
\hline & & R:AGAATTTGTACAGAGGTAATGCACTG & & & \\
\hline \multirow[t]{2}{*}{ TG05-046 } & 5 & F:AAAACATGGCTTACAAACTGG & $(\mathrm{AT})_{8}(\mathrm{~A})_{4}(\mathrm{AT})_{6}(\mathrm{~A})_{9}(\mathrm{AT})_{2}$ & 6-Fam & Dawson et al. (2010) \\
\hline & & R:GCTCAGATAAGGGAGAAAACAG & & & \\
\hline \multirow[t]{2}{*}{ Ase19 } & 3 & F:TAGGGTCCCAGGGAGGAAG & $(\mathrm{CA})_{4} \mathrm{GA}(\mathrm{CA})_{5}$ & 6-Fam & Richardson et al. (2000) \\
\hline & & R:TCTGCCCATTAGGGAAAAGTC & & & \\
\hline \multirow[t]{2}{*}{ Ase18 } & 8 & F:ATCCAGTCTTCGCAAAAGCC & $(\mathrm{GT})_{12}$ & Ned & Richardson et al. (2000) \\
\hline & & R:TGCCCCAGAGGGAAGAAG & & & \\
\hline \multirow[t]{2}{*}{ Ase55 } & 2 & F:GTGTGGACTCTGGTGGCTC & $(\mathrm{GT})_{9}$ & Pet & Richardson et al. (2000) \\
\hline & & R:TCCCAAAGCACTCAAACTAGG & & & \\
\hline
\end{tabular}

Table S5: Prior distributions of the historical parameters used in the scenarios modelled with DIYABC.

\begin{tabular}{|c|c|c|c|c|c|c|c|c|c|c|}
\hline & \multicolumn{4}{|c|}{ Prior set 1} & \multicolumn{6}{|c|}{ Prior set 2} \\
\hline & distribution & $\min$ & $\max$ & mean & $\mathrm{sd}$ & distribution & $\min$ & $\max$ & mean & $\mathrm{sd}$ \\
\hline $\mathrm{N}_{\mathrm{M}}$ & Uniform & 100 & 20000 & & . & Normal & 2 & 30000 & 10000 & 5000 \\
\hline $\mathrm{N}_{\mathrm{RB}}$ & Uniform & 100 & 20000 & & . & Normal & 2 & 30000 & 10000 & 5000 \\
\hline $\mathrm{N}_{\mathrm{RO}}$ & Uniform & 100 & 20000 & & . & Normal & 2 & 30000 & 10000 & 5000 \\
\hline $\mathrm{N}_{\mathrm{RBb}}$ & Uniform & 2 & 1000 & . & . & Normal & 2 & 1500 & 500 & 250 \\
\hline $\mathrm{N}_{\mathrm{R}} \mathrm{O}_{\mathrm{b}}$ & Uniform & 2 & 1000 & . & . & Normal & 2 & 1500 & 500 & 250 \\
\hline $\mathrm{t}_{1}$ & Uniform & 5 & 50 & . & . & Uniform & 5 & 100 & & . \\
\hline$t_{2}$ & Uniform & 5 & 50 & . & . & Uniform & 5 & 100 & & . \\
\hline $\mathrm{t}_{\mathrm{b} 1}$ & Uniform & 0 & 50 & 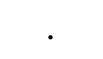 & . & Uniform & 0 & 100 & & . \\
\hline $\mathrm{t}_{\mathrm{b} 2}$ & Uniform & 0 & 50 & . & . & Uniform & 0 & 100 & . & . \\
\hline
\end{tabular}

$\mathrm{N}_{\mathrm{x}}$ : number of individuals in the population $\mathrm{x}$ (constant in time), $\mathrm{N}_{\mathrm{xb}}$ : number of individuals in the population $x$ during the bottleneck following introduction (constant during the whole bottleneck), $\mathrm{t}_{\mathrm{i}}$ : number of generations elapsed between the present and an introduction event or a split $\mathrm{i}, \mathrm{t}_{\mathrm{bi}}$ : number of generations elapsed during the bottleneck following an event $\mathrm{i}$. 
Table S6: Pairwise comparisons of body size (upper part of the table) and beak size (lower part of the table) between sample sites on Reunion conducted with Tuckey's HSD tests.

\begin{tabular}{|c|c|c|c|c|c|c|c|c|c|c|c|}
\hline Whole body & R-W5 & $\mathrm{R}-\mathrm{W} 4$ & R-W3 & $\mathrm{R}-\mathrm{W} 2$ & R-W1 & R-Intro & R-L1 & R-L2 & R-L3 & R-L4 & R-L5 \\
\hline R-W4 & $\mathrm{x}$ & & & & & & & & & & \\
\hline R-W3 & $2.98 \mathrm{e}-02$ & $\mathrm{x}$ & & & & & & & & & \\
\hline R-W2 & $\mathrm{x}$ & $\mathrm{x}$ & $\mathrm{x}$ & & & & & & & & \\
\hline R-W1 & $\mathrm{x}$ & $\mathrm{x}$ & $\mathrm{x}$ & $\mathrm{x}$ & & & & & & & \\
\hline R-Intro & $\mathrm{x}$ & $\mathrm{x}$ & $2.69 \mathrm{e}-03$ & $\mathrm{x}$ & $\mathrm{x}$ & & & & & & \\
\hline R-L1 & $\mathrm{x}$ & $\mathrm{x}$ & $4.77 \mathrm{e}-02$ & $\mathrm{x}$ & $\mathrm{x}$ & $\mathrm{x}$ & & & & & \\
\hline R-L2 & $\mathrm{x}$ & $\mathrm{x}$ & $5.94 \mathrm{e}-03$ & $\mathrm{x}$ & $\mathrm{x}$ & $\mathrm{x}$ & $\mathrm{x}$ & & & & \\
\hline R-L3 & $\mathrm{x}$ & $\mathrm{x}$ & $9.90 \mathrm{e}-03$ & $\mathrm{x}$ & $\mathrm{x}$ & $\mathrm{x}$ & $\mathrm{x}$ & $\mathrm{x}$ & & & \\
\hline R-L4 & $5.54 \mathrm{e}-03$ & $2.69 \mathrm{e}-02$ & $3.14 \mathrm{e}-02$ & $\mathrm{x}$ & $\mathrm{x}$ & $\mathrm{x}$ & $\mathrm{x}$ & $\mathrm{x}$ & $\mathrm{x}$ & & \\
\hline R-L5 & X & X & $<1.00 \mathrm{e}-05$ & $\mathrm{x}$ & $\mathrm{x}$ & $\mathrm{x}$ & $\mathrm{x}$ & $\mathrm{x}$ & $\mathrm{x}$ & $\mathrm{x}$ & \\
\hline R-L6 & $\mathrm{x}$ & $\mathrm{x}$ & $1.01 \mathrm{e}-02$ & $\mathrm{x}$ & $\mathrm{x}$ & $\mathrm{X}$ & $\mathrm{x}$ & $\mathrm{x}$ & $\mathrm{x}$ & $\mathrm{x}$ & $\mathrm{x}$ \\
\hline Beak & R-W5 & R-W4 & R-W3 & R-W2 & R-W1 & R-Intro & R-L1 & R-L2 & R-L3 & R-L4 & R-L5 \\
\hline R-W4 & $\mathrm{x}$ & & & & & & & & & & \\
\hline R-W3 & $\mathrm{x}$ & $\mathrm{x}$ & & & & & & & & & \\
\hline R-W2 & $\mathrm{x}$ & $\mathrm{x}$ & $\mathrm{x}$ & & & & & & & & \\
\hline R-W1 & $\mathrm{x}$ & $\mathrm{x}$ & $\mathrm{x}$ & $\mathrm{x}$ & & & & & & & \\
\hline R-Intro & $\mathrm{x}$ & $\mathrm{x}$ & $\mathrm{x}$ & $\mathrm{x}$ & $\mathrm{x}$ & & & & & & \\
\hline R-L1 & $\mathrm{x}$ & $x$ & $\mathrm{x}$ & $\mathrm{x}$ & $\mathrm{x}$ & $\mathrm{x}$ & & & & & \\
\hline R-L2 & $\mathrm{x}$ & $\mathrm{x}$ & $\mathrm{x}$ & $\mathrm{x}$ & $\mathrm{x}$ & $\mathrm{x}$ & $\mathrm{x}$ & & & & \\
\hline R-L3 & $\mathrm{x}$ & $\mathrm{x}$ & $\mathrm{x}$ & $\mathrm{x}$ & $\mathrm{x}$ & $\mathrm{x}$ & $\mathrm{x}$ & $\mathrm{x}$ & & & \\
\hline R-L4 & $\mathrm{x}$ & $\mathrm{x}$ & $\mathrm{x}$ & $\mathrm{x}$ & $\mathrm{x}$ & $\mathrm{x}$ & $\mathrm{x}$ & $\mathrm{x}$ & $\mathrm{x}$ & & \\
\hline R-L5 & $\mathrm{x}$ & $\mathrm{x}$ & $\mathrm{x}$ & $\mathrm{x}$ & $\mathrm{x}$ & $\mathrm{x}$ & $\mathrm{x}$ & $\mathrm{x}$ & $\mathrm{x}$ & $\mathrm{x}$ & \\
\hline R-L6 & $\mathrm{x}$ & $\mathrm{x}$ & $\mathrm{x}$ & $\mathrm{x}$ & $\mathrm{x}$ & $\mathrm{x}$ & $\mathrm{x}$ & $\mathrm{x}$ & $\mathrm{x}$ & $\mathrm{x}$ & $\mathrm{x}$ \\
\hline
\end{tabular}

$\mathrm{x}$ Non-significant differences.

Table S7: Test for allometry: effect of geographic origin, sample site and sex on the conformation variables for the whole body data set (ANCOVAs, upper part of the table) and for the beak data set (ANCOVAs, lower part of the table). Conformation variables: first axes representing $95 \%$ of the total variance of the PCAs performed on measurements for the whole body data set and on geometric morphometric coordinates for the beak data set.

\begin{tabular}{|c|c|c|c|c|c|c|c|}
\hline $\begin{array}{l}\text { Whole } \\
\text { body }\end{array}$ & $\begin{array}{l}\text { Geo.origin:site:sex } \\
\text { :size }\end{array}$ & $\begin{array}{l}\text { Geo.origin:sex: } \\
\text { size }\end{array}$ & $\begin{array}{l}\text { Geo.origin:site: } \\
\text { sex }\end{array}$ & $\begin{array}{l}\text { Geo.origin: } \\
\text { site:size }\end{array}$ & $\begin{array}{l}\text { Size: } \\
\text { sex }\end{array}$ & $\begin{array}{l}\text { Geo.origin: } \\
\text { sex }\end{array}$ & $\begin{array}{c}\text { Geo.origin: } \\
\text { size }\end{array}$ \\
\hline Axis 1 & 0.53 & 0.85 & 0.77 & 0.73 & 0.45 & $8.04 \mathrm{e}-02$ & $2.28 \mathrm{e}-07 *$ \\
\hline Axis 2 & 0.59 & 0.94 & 0.78 & 0.79 & 0.11 & 0.27 & 0.11 \\
\hline Axis 3 & 0.31 & 0.79 & 0.48 & 0.23 & 0.45 & 0.50 & 0.29 \\
\hline Beak & $\begin{array}{c}\text { Geo.origin:site:sex } \\
\text { :size } \\
\end{array}$ & $\begin{array}{l}\text { Geo.origin:sex: } \\
\text { size } \\
\end{array}$ & $\begin{array}{l}\text { Geo.origin:site: } \\
\text { sex } \\
\end{array}$ & $\begin{array}{l}\text { Geo.origin: } \\
\text { site:size } \\
\end{array}$ & $\begin{array}{l}\text { Size: } \\
\text { sex }\end{array}$ & $\begin{array}{l}\text { Geo.origin: } \\
\text { sex }\end{array}$ & $\begin{array}{c}\text { Geo.origin: } \\
\text { size }\end{array}$ \\
\hline Axis 1 & 0.83 & 0.66 & 0.39 & 0.89 & 0.89 & 0.85 & 0.87 \\
\hline Axis 2 & 0.59 & 0.87 & 0.10 & 0.72 & 0.49 & 0.29 & $5.44 \mathrm{e}-02$ \\
\hline Axis 3 & 0.68 & $7.93 e-02$ & $7.97 \mathrm{e}-02$ & 0.81 & $1.85 \mathrm{e}-02 *$ & 0.15 & 0.36 \\
\hline Axis 4 & 0.72 & 0.60 & 0.26 & $5.51 \mathrm{e}-02$ & $4.34 \mathrm{e}-02 *$ & 0.21 & 0.24 \\
\hline
\end{tabular}

* P-values under the significance threshold. A significant interaction between global geographic origin / site and size (highlighted in bold) indicates that there is a difference in allometry between geographic groups. 
Table S8: Pairwise comparisons of body conformation (upper part of the table) and beak conformation (lower part of the table) between sample sites on Reunion conducted with Hotelling's T-squared tests.

\begin{tabular}{|c|c|c|c|c|c|c|c|c|c|c|c|}
\hline Whole body & R-W5 & $\mathrm{R}-\mathrm{W} 4$ & R-W3 & R-W2 & R-W1 & R-Intro & R-L1 & R-L2 & R-L3 & R-L4 & R-L5 \\
\hline $\mathrm{R}-\mathrm{W} 4$ & $\mathrm{x}$ & & & & & & & & & & \\
\hline R-W3 & $* * *$ & $\mathrm{x}$ & & & & & & & & & \\
\hline R-W2 & $\mathrm{x}$ & $\mathrm{x}$ & $\mathrm{x}$ & & & & & & & & \\
\hline R-W1 & $\mathrm{x}$ & $\mathrm{x}$ & $\mathrm{x}$ & $\mathrm{x}$ & & & & & & & \\
\hline R-Intro & $\mathrm{x}$ & $\mathrm{x}$ & $* * *$ & $\mathrm{x}$ & $\mathrm{x}$ & & & & & & \\
\hline R-L1 & $\mathrm{x}$ & $\mathrm{x}$ & $* * *$ & $\mathrm{x}$ & $\mathrm{x}$ & $\mathrm{x}$ & & & & & \\
\hline R-L2 & $\mathrm{x}$ & $\mathrm{x}$ & $\mathrm{x}$ & $\mathrm{x}$ & $\mathrm{x}$ & $\mathrm{x}$ & $\mathrm{x}$ & & & & \\
\hline R-L3 & $\mathrm{x}$ & $\mathrm{x}$ & $* * *$ & $\mathrm{x}$ & $\mathrm{x}$ & $\mathrm{x}$ & $\mathrm{x}$ & $\mathrm{x}$ & & & \\
\hline R-L4 & $\mathrm{x}$ & $* * *$ & $* * *$ & $\mathrm{x}$ & $* * *$ & $\mathrm{x}$ & $\mathrm{x}$ & $\mathrm{x}$ & $\mathrm{x}$ & & \\
\hline R-L5 & $\mathrm{x}$ & $\mathrm{x}$ & $* * *$ & $\mathrm{x}$ & $\mathrm{x}$ & $\mathrm{x}$ & $\mathrm{x}$ & $\mathrm{x}$ & $\mathrm{x}$ & $\mathrm{x}$ & \\
\hline R-L6 & $\mathrm{x}$ & $\mathrm{x}$ & $\mathrm{x}$ & $\mathrm{x}$ & $\mathrm{x}$ & $\mathrm{x}$ & $\mathrm{x}$ & $\mathrm{x}$ & $\mathrm{x}$ & $\mathrm{x}$ & $\mathrm{x}$ \\
\hline Beak (males) & R-W5 & R-W4 & R-W3 & R-W2 & R-W1 & R-Intro & R-L1 & R-L2 & R-L3 & R-L4 & R-L5 \\
\hline R-W4 & $\mathrm{x}$ & & & & & & & & & & \\
\hline R-W3 & $\mathrm{x}$ & $\mathrm{x}$ & & & & & & & & & \\
\hline R-W2 & $\mathrm{x}$ & $\mathrm{x}$ & $\mathrm{x}$ & & & & & & & & \\
\hline R-W1 & $\mathrm{x}$ & $\mathrm{x}$ & $\mathrm{x}$ & $\mathrm{x}$ & & & & & & & \\
\hline R-Intro & $\mathrm{x}$ & $\mathrm{x}$ & $\mathrm{x}$ & $\mathrm{x}$ & $\mathrm{x}$ & & & & & & \\
\hline R-L1 & $\mathrm{x}$ & $\mathrm{x}$ & $\mathrm{x}$ & $\mathrm{x}$ & $\mathrm{x}$ & $\mathrm{x}$ & & & & & \\
\hline R-L2 & $\mathrm{x}$ & $\mathrm{x}$ & $\mathrm{x}$ & $\mathrm{x}$ & $\mathrm{x}$ & $\mathrm{x}$ & $\mathrm{x}$ & & & & \\
\hline R-L3 & $\mathrm{x}$ & $* * *$ & $\mathrm{x}$ & $* * *$ & $\mathrm{x}$ & $\mathrm{x}$ & $\mathrm{x}$ & $\mathrm{x}$ & & & \\
\hline R-L4 & $* * *$ & $\mathrm{x}$ & $\mathrm{x}$ & $* * *$ & $\mathrm{x}$ & $\mathrm{x}$ & $\mathrm{x}$ & $\mathrm{x}$ & $* * *$ & & \\
\hline R-L5 & $\mathrm{x}$ & $\mathrm{x}$ & $\mathrm{x}$ & $\mathrm{x}$ & $\mathrm{x}$ & $\mathrm{x}$ & $\mathrm{x}$ & $* * *$ & $\mathrm{x}$ & $* * *$ & \\
\hline R-L6 & $\mathrm{x}$ & $\mathrm{x}$ & $\mathrm{x}$ & $\mathrm{x}$ & $\mathrm{x}$ & $\mathrm{x}$ & $\mathrm{x}$ & $\mathrm{x}$ & $\mathrm{x}$ & $\mathrm{x}$ & $\mathrm{x}$ \\
\hline Beak (females) & R-W5 & R-W4 & R-W3 & R-W2 & R-W1 & R-Intro & R-L1 & R-L2 & R-L3 & R-L4 & R-L5 \\
\hline R-W4 & $\mathrm{x}$ & & & & & & & & & & \\
\hline R-W3 & $\mathrm{x}$ & $\mathrm{x}$ & & & & & & & & & \\
\hline R-W2 & $\mathrm{x}$ & $\mathrm{x}$ & $\mathrm{x}$ & & & & & & & & \\
\hline R-W1 & $\mathrm{x}$ & $\mathrm{x}$ & $\mathrm{x}$ & $\mathrm{x}$ & & & & & & & \\
\hline R-Intro & $\mathrm{x}$ & $\mathrm{x}$ & $\mathrm{x}$ & $\mathrm{x}$ & $* * *$ & & & & & & \\
\hline R-L1 & $\mathrm{x}$ & $\mathrm{x}$ & $\mathrm{x}$ & $\mathrm{x}$ & $\mathrm{x}$ & $\mathrm{x}$ & & & & & \\
\hline R-L2 & $\mathrm{x}$ & $\mathrm{x}$ & $\mathrm{x}$ & $\mathrm{x}$ & $\mathrm{x}$ & $\mathrm{x}$ & $\mathrm{x}$ & & & & \\
\hline R-L3 & $\mathrm{x}$ & $\mathrm{x}$ & $\mathrm{x}$ & $\mathrm{x}$ & $\mathrm{x}$ & $\mathrm{x}$ & $\mathrm{x}$ & $\mathrm{x}$ & & & \\
\hline R-L4 & $\mathrm{x}$ & $\mathrm{x}$ & $\mathrm{x}$ & $\mathrm{x}$ & $\mathrm{x}$ & $\mathrm{x}$ & $\mathrm{x}$ & $\mathrm{x}$ & $\mathrm{x}$ & & \\
\hline R-L5 & $* * *$ & $* * *$ & $\mathrm{x}$ & $\mathrm{x}$ & $\mathrm{x}$ & $\mathrm{x}$ & $\mathrm{x}$ & $\mathrm{x}$ & $\mathrm{x}$ & $\mathrm{x}$ & \\
\hline R-L6 & $\mathrm{x}$ & $\mathrm{x}$ & $\mathrm{x}$ & $x$ & $\mathrm{x}$ & $x$ & $\mathrm{x}$ & $x$ & $\mathrm{x}$ & $\mathrm{x}$ & $\mathrm{x}$ \\
\hline
\end{tabular}


Table S9: Posterior probabilities of the scenarios compared with the $\mathrm{ABC}$ analysis of the microsatellite data set for each set of priors. These posterior probabilities were assessed using a polychotomous logistic regression on the 0.1 and $1 \%$ simulated data sets closest to the observed data set.

$$
\text { Prior set } 1 \quad \text { Prior set } 1
$$

\begin{tabular}{ccccc} 
Scenario & P 0.1\% & P 1\% & P 0.1\% & P 1\% \\
\hline A & 0.13 & 0.14 & 0.09 & 0.08 \\
B & 0.10 & 0.11 & 0.06 & 0.07 \\
C & 0.57 & 0.55 & 0.55 & 0.58 \\
D & 0.21 & 0.21 & 0.30 & 0.27 \\
\hline
\end{tabular}

Table S10: Probability distributions of the demographic parameters of scenario $\mathrm{C}$ based on the $1 \%$ of simulated data sets closest to the real data set.

\begin{tabular}{llllllllll} 
Parameter & mean & median & mode & $\mathrm{q} 025$ & $\mathrm{q} 050$ & $\mathrm{q} 250$ & $\mathrm{q} 750$ & $\mathrm{q} 950$ & $\mathrm{q} 975$ \\
\hline $\mathrm{N}_{\mathrm{M}}$ & $1.60 \mathrm{e}+003$ & $1.44 \mathrm{e}+003$ & $1.10 \mathrm{e}+003$ & $5.25 \mathrm{e}+002$ & $6.43 \mathrm{e}+002$ & $1.06 \mathrm{e}+003$ & $1.96 \mathrm{e}+003$ & $3.04 \mathrm{e}+003$ & $3.50 \mathrm{e}+003$ \\
$\mathrm{~N}_{\mathrm{RO}}$ & $9.20 \mathrm{e}+003$ & $8.70 \mathrm{e}+003$ & $2.16 \mathrm{e}+003$ & $8.24 \mathrm{e}+002$ & $1.17 \mathrm{e}+003$ & $4.14 \mathrm{e}+003$ & $1.39 \mathrm{e}+004$ & $1.87 \mathrm{e}+004$ & $1.94 \mathrm{e}+004$ \\
$\mathrm{~N}_{\mathrm{RB}}$ & $9.92 \mathrm{e}+003$ & $9.81 \mathrm{e}+003$ & $1.74 \mathrm{e}+003$ & $9.77 \mathrm{e}+002$ & $1.43 \mathrm{e}+003$ & $4.91 \mathrm{e}+003$ & $1.48 \mathrm{e}+004$ & $1.89 \mathrm{e}+004$ & $1.95 \mathrm{e}+004$ \\
$\mathrm{t} 2$ & $2.58 \mathrm{e}+001$ & $2.55 \mathrm{e}+001$ & $2.24 \mathrm{e}+001$ & $8.32 \mathrm{e}+000$ & $1.03 \mathrm{e}+001$ & $1.85 \mathrm{e}+001$ & $3.29 \mathrm{e}+001$ & $4.19 \mathrm{e}+001$ & $4.42 \mathrm{e}+001$ \\
$\mathrm{t}_{\mathrm{b} 2}$ & $2.33 \mathrm{e}+001$ & $2.36 \mathrm{e}+001$ & $2.49 \mathrm{e}+001$ & $2.96 \mathrm{e}+000$ & $5.28 \mathrm{e}+000$ & $1.45 \mathrm{e}+001$ & $3.20 \mathrm{e}+001$ & $4.08 \mathrm{e}+001$ & $4.28 \mathrm{e}+001$ \\
$\mathrm{~N}_{\mathrm{ROb}}$ & $2.80 \mathrm{e}+002$ & $2.14 \mathrm{e}+002$ & $1.04 \mathrm{e}+002$ & $2.45 \mathrm{e}+001$ & $3.72 \mathrm{e}+001$ & $1.10 \mathrm{e}+002$ & $3.84 \mathrm{e}+002$ & $7.63 \mathrm{e}+002$ & $8.64 \mathrm{e}+002$ \\
$\mathrm{t} 1$ & $3.93 \mathrm{e}+001$ & $4.09 \mathrm{e}+001$ & $4.76 \mathrm{e}+001$ & $2.06 \mathrm{e}+001$ & $2.36 \mathrm{e}+001$ & $3.43 \mathrm{e}+001$ & $4.59 \mathrm{e}+001$ & $4.93 \mathrm{e}+001$ & $5.00 \mathrm{e}+001$ \\
$\mathrm{t}_{\mathrm{b} 1}$ & $3.07 \mathrm{e}+001$ & $3.25 \mathrm{e}+001$ & $4.17 \mathrm{e}+001$ & $6.43 \mathrm{e}+000$ & $9.51 \mathrm{e}+000$ & $2.32 \mathrm{e}+001$ & $3.97 \mathrm{e}+001$ & $4.61 \mathrm{e}+001$ & $4.72 \mathrm{e}+001$ \\
$\mathrm{~N}_{\mathrm{RBb}}$ & $3.24 \mathrm{e}+002$ & $2.65 \mathrm{e}+002$ & $1.37 \mathrm{e}+002$ & $3.51 \mathrm{e}+001$ & $5.18 \mathrm{e}+001$ & $1.48 \mathrm{e}+002$ & $4.47 \mathrm{e}+002$ & $8.10 \mathrm{e}+002$ & $9.02 \mathrm{e}+002$ \\
\hline $\mathrm{N}_{\mathrm{x}} \mathrm{n}$ & & & & & & &
\end{tabular}
$\mathrm{N}_{\mathrm{x}}$ : number of individuals in the population $\mathrm{x}$ (constant in time), $\mathrm{N}_{\mathrm{xb}}$ : number of individuals in the population $\mathrm{x}$ during the bottleneck following introduction (constant during the whole bottleneck), $\mathrm{t}_{\mathrm{i}}$ : number of generations between present and an introduction event or a split $\mathrm{i}, \mathrm{t}_{\mathrm{bi}}$ : number of generations during the bottleneck following an introduction event $i$. 


\section{Supplementary figures}

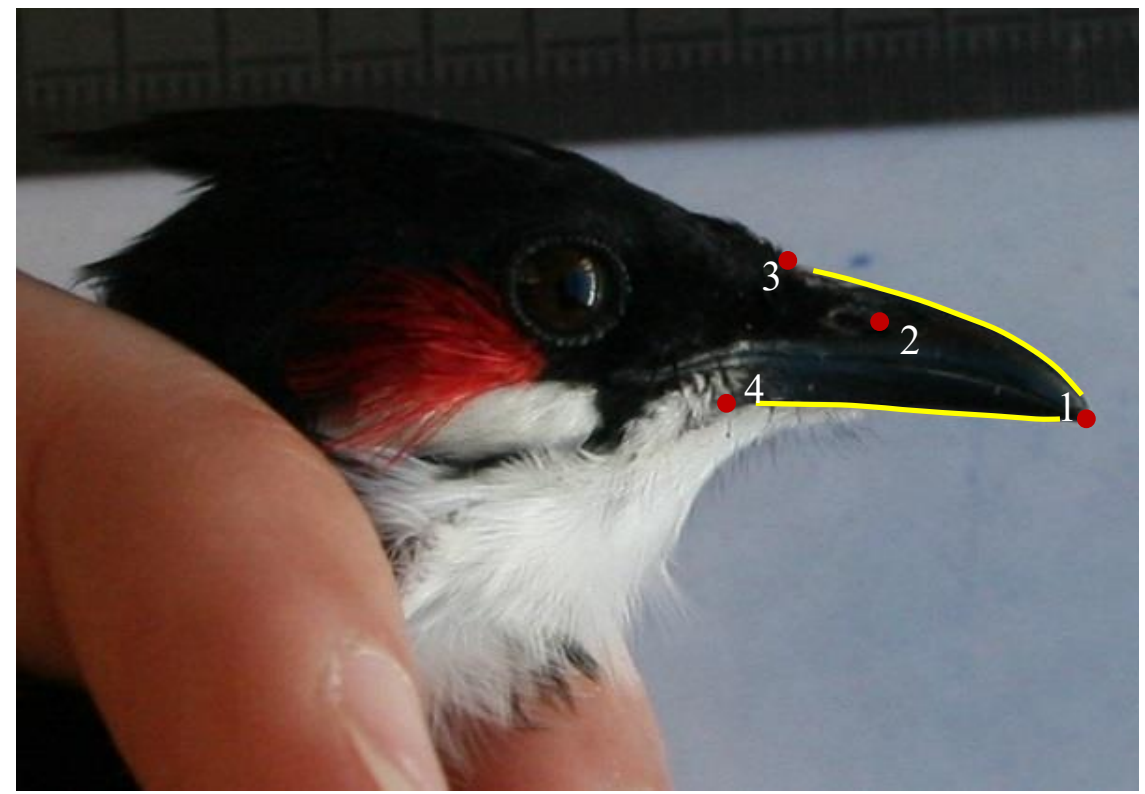

Fig. S1: Position of the four landmarks and the two outline curves (10 semi-landmarks equally spaced for each curve) digitized on beak pictures to obtain the geometric morphometric data set.

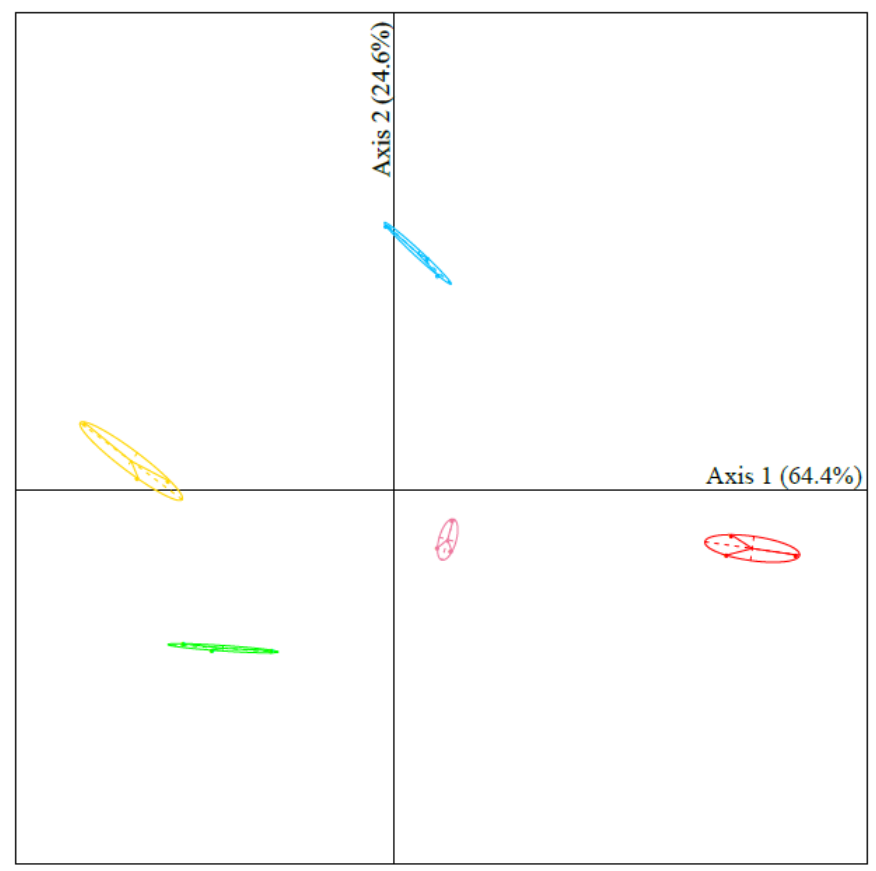

Fig. S2: Results of the PCA performed on beak conformation variables to test the repeatability of the digitization process (first two axes). Each color represents an individual. Three digitization repetitions where done for each individual. Variation is much lower within repetitions than between individuals, indicating a good repeatability of the digitization process. 

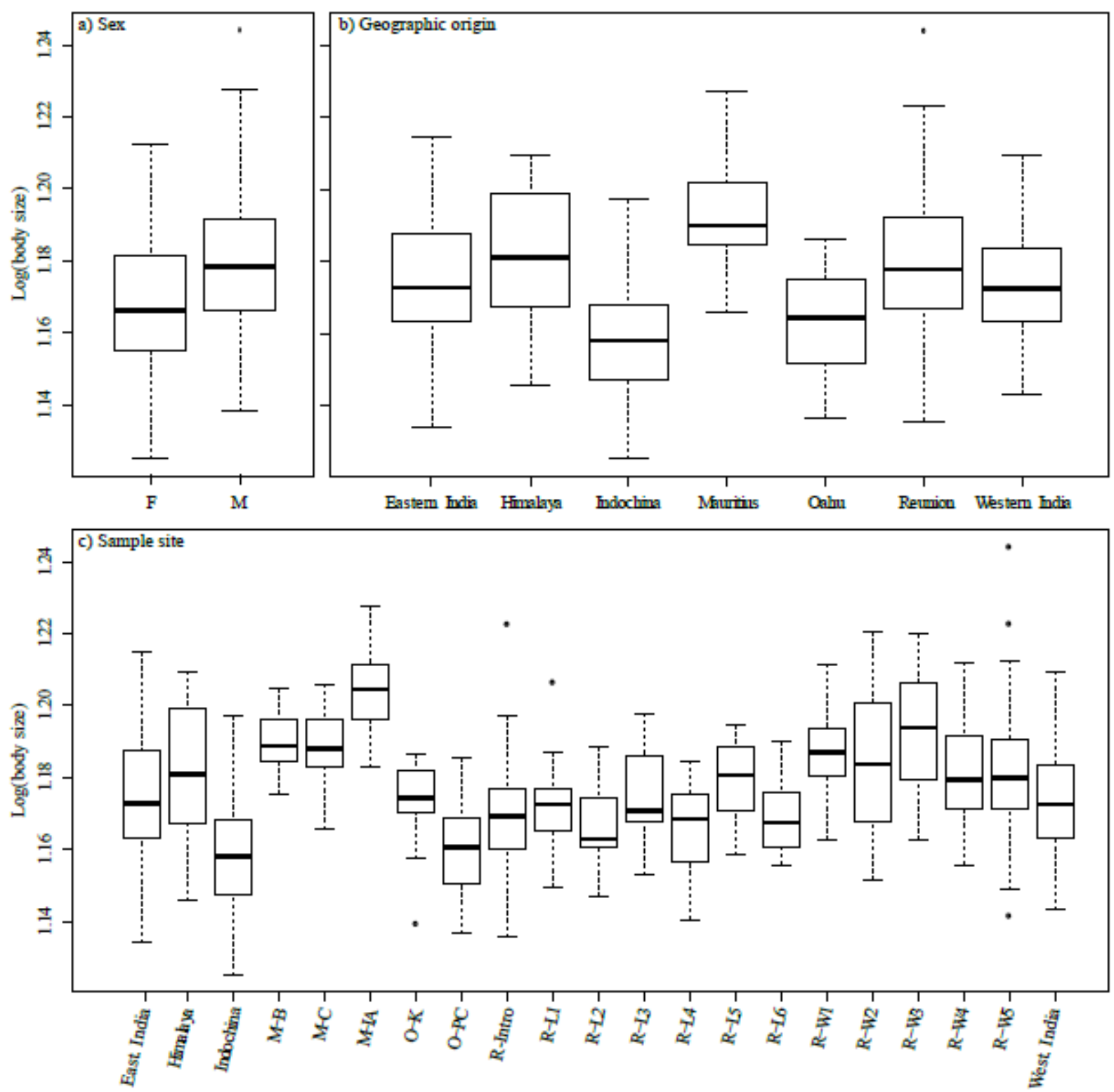

Fig. S3: boxplots of the body size of individuals according to a) their sex, b) their geographic origin, and c) their sample site. 

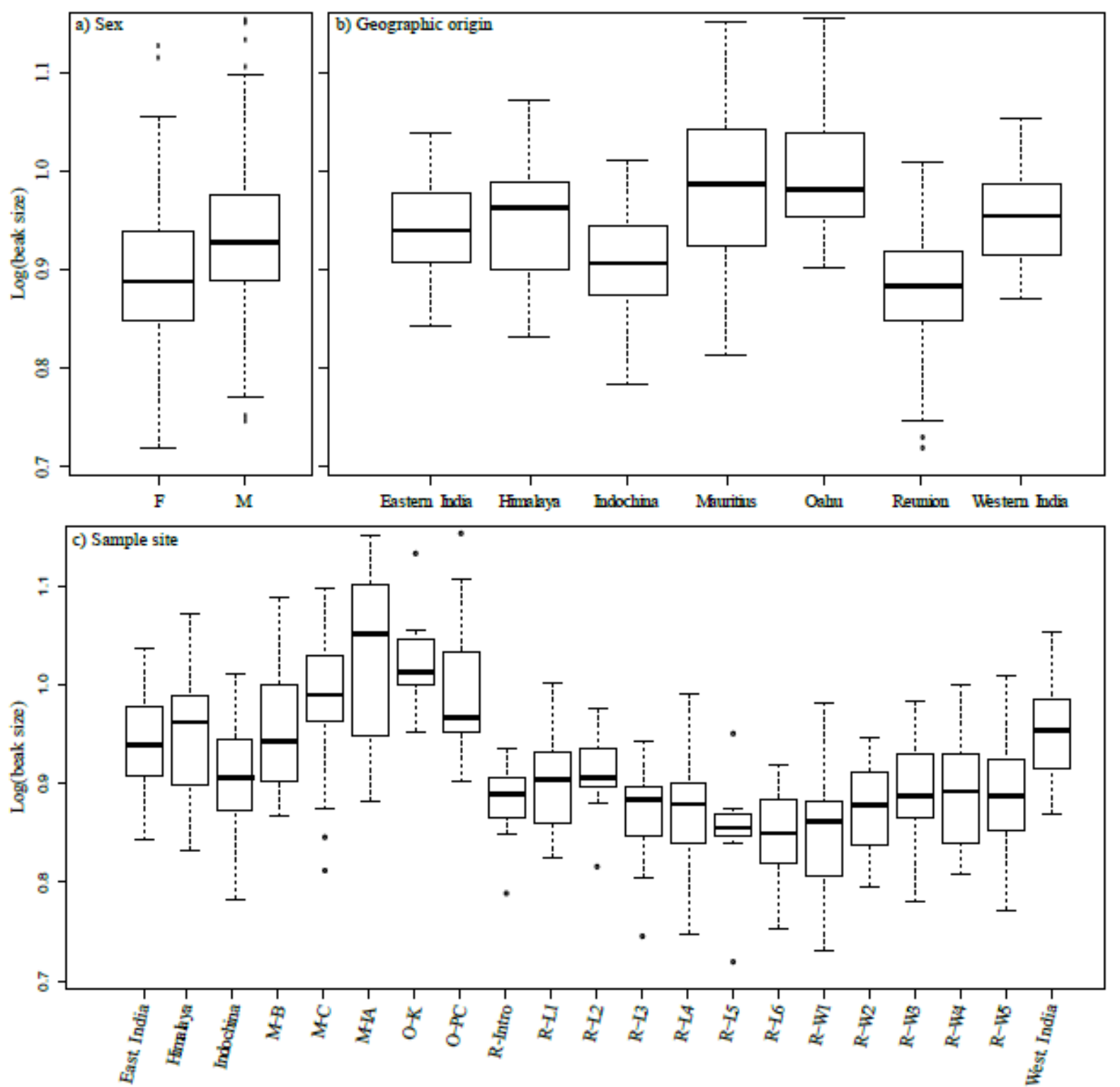

Fig. S4: boxplots of the beak size of individuals according to a) their sex, b) their geographic origin, and c) their sample site. 

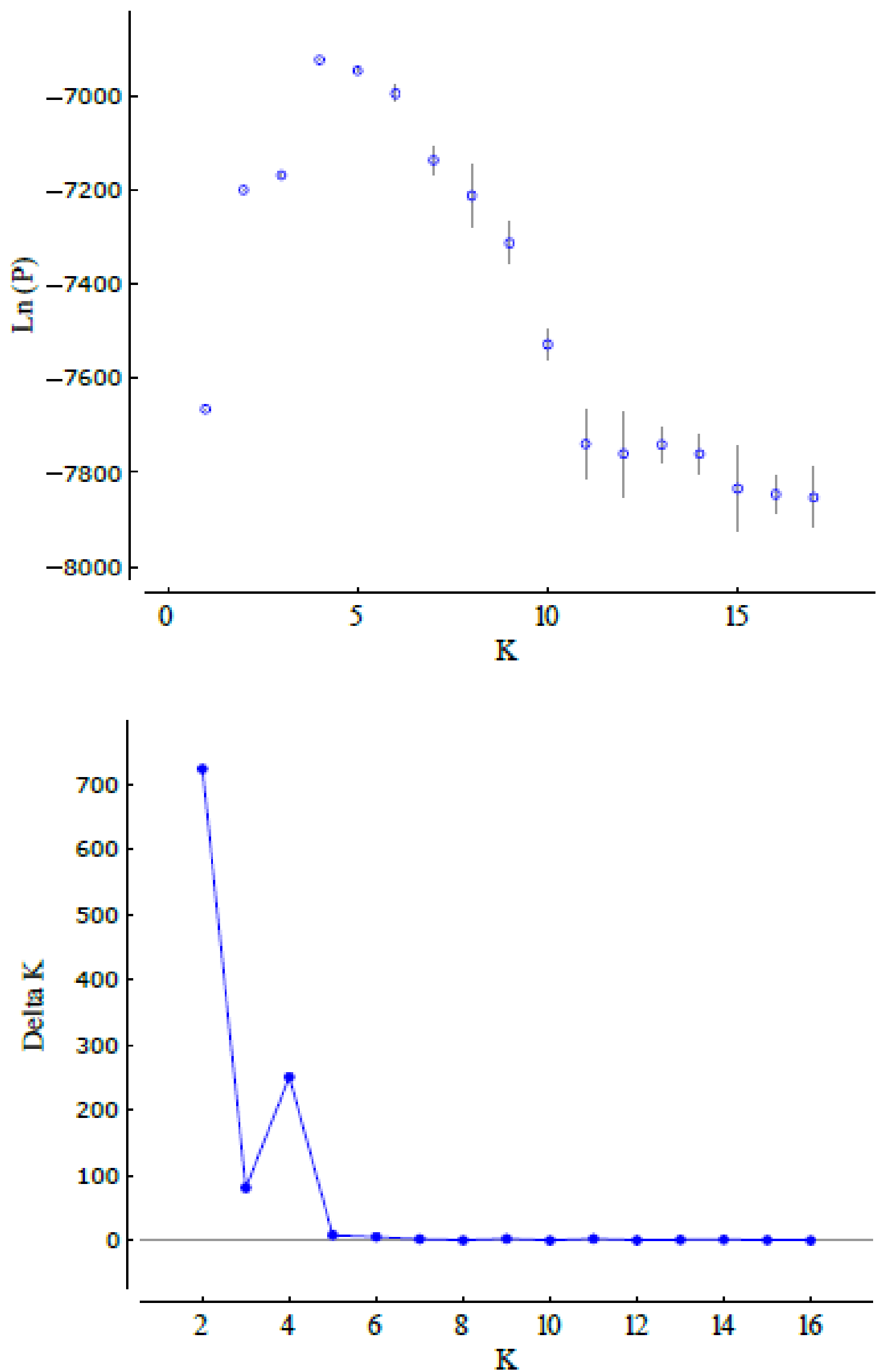

Fig. S5: Mean log likelihood (left) and delta K (right) of the simulations run with STRUCTURE over 10 runs for each number of clusters. 


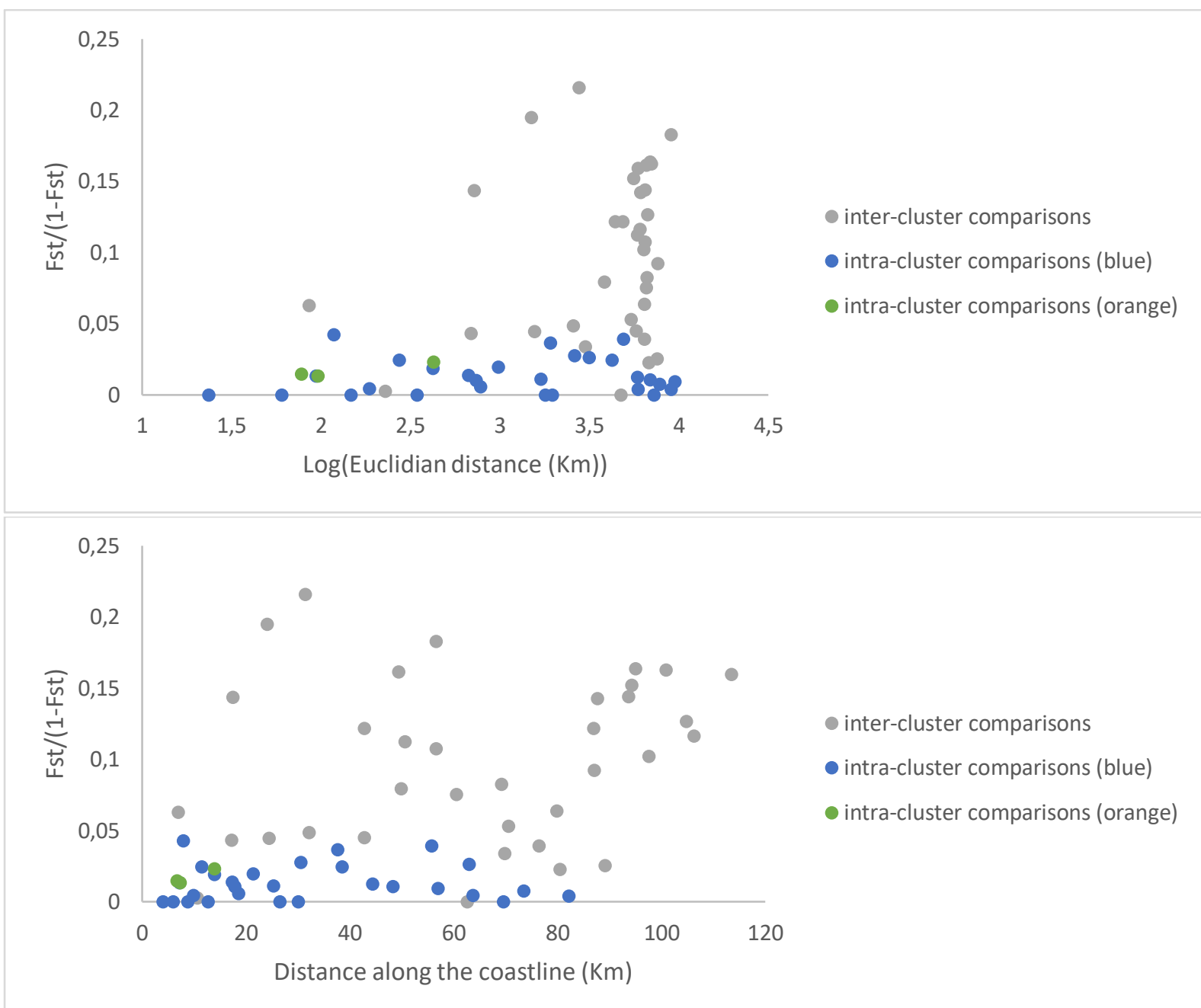

Fig. S6 : Plots of the pairwise genetic distance between sample sites on Reunion against the pairwise geographic distance between sample sites. The geographic distance between sample sites are either Euclidian distances (top graphic) or disatnces calculated following the coastline (bottom graphic). Gey dots represent pairwise comparisons between sites belonging to different clusters whereas orange and blue dots represent pairwise comparisons between sites belonging to the orange cluster and the blue cluster respectively. 

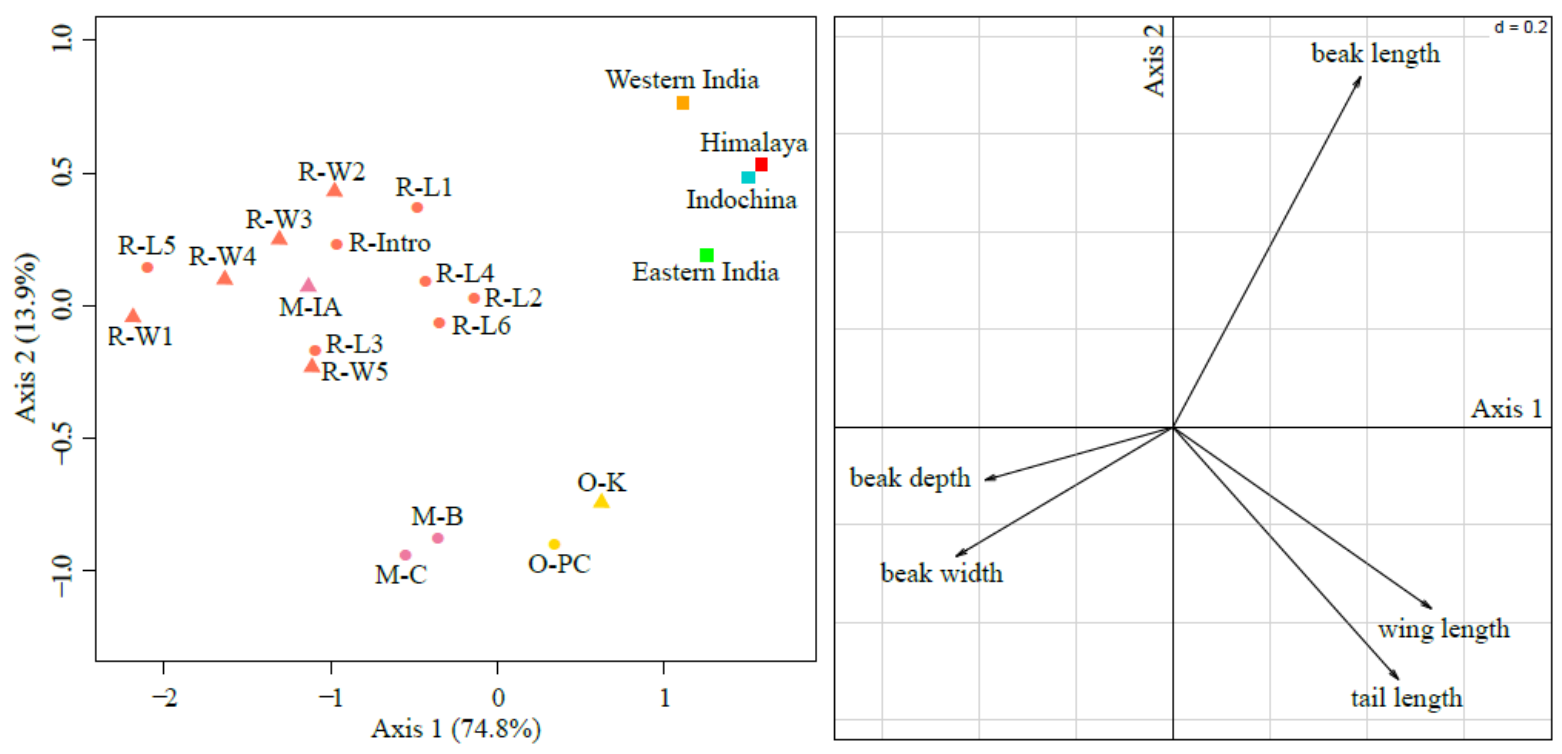

Fig. S7: Morphological divergence between invasive populations and their source in the native range. Left: Morphospace defined by the first two axes of the PCA on conformation variables for the whole body data set. Only the mean individual is represented for each sample site or phylogeographic clade (native populations - square symbols). Triangles represent sample sites located on the windward coasts of the islands, circles represent sample sites located on the leeward coasts of the islands. Right: correlation between the conformation variables and the first two axes of the PCA. 


\section{References}

Akaike H (1974) A new look at the statistical model identification. IEEE Transactions on Automatic Control, 19, 716-723.

Dawson DA, Hanotte O, Greig C, Stewart IRK, Burke T (2000) Polymorphic microsatellites in the blue tit Parus caeruleus and their cross-species utility in 20 songbird families. Molecular ecology, 9, 1919-1952.

Dawson DA, Horsburgh GJ, Küpper C et al. (2010) New methods to identify conserved microsatellite loci and develop primer sets of high cross-species utility - as demonstrated for birds. Molecular ecology resources, 10, 475-494.

Huelsenbeck JP, Ronquist F (2001) MRBAYES: Bayesian inference of phylogenetic trees. Bioinformatics, 17, 754-755.

Lokugalappatti LGS, Feldheim KA, Sellas AB, Bowie RCK (2008) Isolation and characterization of 10 tetranucleotide microsatellite loci from the yellow-streaked greenbul (Phyllastrephus flavostriatus) and cross-species amplification in four closely related taxa. Molecular ecology resources, 8, 622-624.

Nylander JAA (2004) MrModeltest v2. Program distributed by the author. Evolutionary Biology Centre, Uppsala University.

Nylander JAA, Wilgenbusch JC, Warren DL, Swofford DL (2008) AWTY (are we there yet?): a system for graphical exploration of MCMC convergence in Bayesian phylogenetics. Bioinformatics, 24, 581-583.

Richardson DS, Jury FL, Dawson DA et al. (2000) Fifty Seychelles warbler (Acrocephalus sechellensis) microsatellite loci polymorphic in Sylviidae species and their cross-species amplification in other passerine birds. Molecular ecology, 9, 2155-2234.

Ronquist F, Huelsenbeck JP (2003) MrBayes 3: Bayesian phylogenetic inference under mixed models. Bioinformatics, 19, 1572-1574.

Stamatakis A (2006) RAxML-VI-HPC: maximum likelihood-based phylogenetic analyses with thousands of taxa and mixed models. Bioinformatics, 22, 2688-2690.

Swofford DL (2003) PAUP*. Phylogenetic Analysis Using Parsimony (*and Other Methods). Sinauer Associates, Sunderland, Massachusetts. 